\title{
Applications of ZnO Nanorods and Nanowires - A Review
}

\author{
B.S. WitKOWSKI* \\ Institute of Physics, Polish Academy of Sciences, Aleja Lotnikow 32/46, PL-02668 Warsaw, Poland
}

(Received December 11, 2018)

\begin{abstract}
This paper contains a review describing the various potential applications of $\mathrm{ZnO}$ nanorods in many different devices such as light emitters (light emitting diodes and lasers) and detectors (on single nanorod or nanorods matrices), photovoltaic cells (dye-sensitized, perovskite-based, thin film, organic and silicon solar cells), photocatalytic applications, field emitters, field effect transistors, chemical and biological sensors, and electric nanogenerators. The review describes state of art in this field from more than twenty years perspective, presenting problems and challenges to be solved.
\end{abstract}

DOI: 10.12693/APhysPolA.134.1226

PACS/topics: ZnO nanorods, ZnO nanowires, photovoltaic cells, solar cells, LED, laser, detector, sensor, photocatalytic, field emission, field effect transistor, nanogenerator

\section{Introduction}

Zinc oxide is a semiconductor with a direct band gap of $3.37 \mathrm{eV}$ of high transparency and high $n$-type conductivity [1]. This means that $\mathrm{ZnO}$ is suitable for use in a wide range of optical and electronic applications. It is also notable that $\mathrm{ZnO}$ is piezoelectric and exhibits high mechanical, thermal, and chemical stability [2]. $\mathrm{ZnO}$ is also biocompatible, and thus does not pose a threat to people and animals [3]. The great advantage of $\mathrm{ZnO}$ is the ease of crystallization of various forms of nanostructures by many methods (chemical vapor deposition (CVD) [49], thermal evaporation [7, 10-14], molecular beam epitaxy (MBE) [15], pulsed laser deposition [1], hydrothermal [16], atomic layer deposition (ALD) [17] and other methods [18]), some of which are extremely cost-effective and environmentally friendly [19]. Thus, a wide range of possible applications of $\mathrm{ZnO}$ layers and nanostructures are under investigation. In this review, we focus on possible applications of $\mathrm{ZnO}$ nanorods and nanowires (NRs). This review is organized as follows: light emitters (light-emitting-diodes (LED) and lasers), light detectors, photovoltaic (PV) cells, photocatalytic applications, field emission (FE), field effect transistors (FET), chemical and biological sensors, and power nanogenerators.

\section{Light emitters \\ 2.1. Light emitting diodes}

LED technology was originally developed from highefficiency electroluminescence (EL) semiconductor devices in early 1962 [20]. The high brightness, high efficiency and long durability of LEDs renders them ideal for displays and solid-state lighting and their share of the market for light emitters is growing constantly.

$\mathrm{ZnO}$ NRs, after GaN structures, are the top choice for new short wavelength LED and laser diode applications not only because of their superior properties,

*e-mail: bwitkow@ifpan.edu.pl with their wide band-gap (3.37 eV) and a large excitonbinding energy $(60 \mathrm{meV})$ [21], but also due to their being easy to grow via chemical and physical vapor-phase approaches [22, 23]. Independent $\mathrm{ZnO}$-based nanostructures can easily be formed, including NRs. It is known that $\mathrm{ZnO}$ NRs can be grown following a designed pattern into aligned arrays on almost any substrate in any shape. The energy bandgap can be expanded by substituting a small amount of $\mathrm{Mg}$ or reduced by adding $\mathrm{Cd}[24,25]$. However, $p$-type $\mathrm{ZnO}$ materials with sufficiently high conductivity and carrier density are still no guarantee of stability and reproducibility, and the $\mathrm{ZnO}$ homojunctions are not yet practically applicable to LEDs.

Heterojunction diodes based on $\mathrm{ZnO}$ film/GaN film structures have been suggested in order to exploit the advantages of $\mathrm{ZnO}$, but heterojunction diodes have low efficiency because of the high energy barrier at the junction interface. This limitation of current thinfilm technology can be surmounted by employing $\mathrm{ZnO}$ NRs which have superior properties, such as high crystalline quality, large surface area, and the quantum confinement effect.

The first attempts to create luminescent diodes using $\mathrm{ZnO}$ were heterostructures, in which $\mathrm{ZnO}$ NRs arrays and polycrystalline $n-\mathrm{ZnO}$ were grown on $\mathrm{Mg}$-doped $p$ GaN films by the CVD method [26]. Electroluminescence emission at $386 \mathrm{~nm}$ wavelength was observed under forward bias in the heterojunction diodes and UVviolet light emerged from the $\mathrm{ZnO}$ NRs. Satisfactory emission was achieved only after thermal treatment in hydrogen ambient to increase the electron injection rate from the $n-\mathrm{ZnO}$ films into the $\mathrm{ZnO}$ NRs. The high concentration of electrons supplied from the $n$ - $\mathrm{ZnO}$ films activated the radiative recombination in the $\mathrm{ZnO} \mathrm{NRs}$ and increased the light-emitting efficiency. Very similar approaches were also used in the following years, i.e. in work [27], but in this case, due to impurities and defects in the materials, the light emission was poor and in a wide visible range. This kind of structure is still under investigation, but with minor changes. For example, in work [28], the method for growing $\mathrm{ZnO}$ NRs was nanoparticle assisted pulsed laser deposition. The 
radiative electron-hole recombination was taken in the $\mathrm{ZnO} \mathrm{NRs}$ due to the small energy barrier for holes. The $p-\mathrm{GaN} / n-\mathrm{ZnO}$ heterojunction diodes with use of NRs exhibited improved EL emission in UV and blue color compared to those of the film-based $\mathrm{GaN} / \mathrm{ZnO}$ heterojunction diodes.

A high-brightness LED based on GaN/ZnO NRs heterojunction was achieved in a similar structure, but the spaces between the NRs were filled with organic material - A11 poly(methyl methacrylate) (PMMA), although this material did not take an active part in the junction and emission [29]. A blue shift was observed in the EL with the increase of bias voltage, indicating the modification of external voltage to the band profile in the depletion region. Nevertheless, efficient and stable emission in the near $\mathrm{UV} /$ violet range was obtained and presented the first hybrid heterojunction LED device.

$\mathrm{ZnO}$ NRs were also used in GaN LEDs but not as an active part in the $p-n$ junction, but as an emission amplifier. Work [30] presented the enhanced light output of GaN-based LEDs with vertically aligned ZnO NRs arrays grown by metal organic vapor phase epitaxy (MOVPE) directly on a $p$-GaN layer (next to the electric contact). Compared to conventional GaN LEDs, the light output of GaN LEDs with ZnO NRs arrays increased up to $50 \%$ and $100 \%$ at applied currents of 20 and $50 \mathrm{~mA}$, respectively. The authors claimed that the electrical field of GaN LEDs can be changed by growing $\mathrm{ZnO}$ nanorods on $p$-GaN, and that with the reduction in internal polarization, GaN LEDs with $\mathrm{ZnO}$ nanorods are very promising as high-efficiency LEDs. These results indicate that the ZnO NR arrays on GaN LEDs result in a decrease in the total internal reflection of the generated light in the active region of the LED. Also note that the operating voltage of the GaN LEDs with ZnO NRs is higher than that of the LEDs without ZnO NRs. This example shows that without changing the LED structure, by growing $\mathrm{ZnO}$ NRs it is easy to achieve higher-brightness LEDs. There were also reports about a dramatic increase in the light extraction efficiency of GaN-based blue LEDs by $\mathrm{ZnO}$ NRs arrays grown on a planar indium tin oxide (ITO) transparent electrode [31]. The light output efficiency of these LEDs was increased by about $57 \%$ with no increase in forward voltage over the conventional LEDs with planar ITO. The increased light extraction by the ZnO NR arrays is due to the formation of sidewalls and a rough surface, resulting in a multiple photon scattering at the LED surface.

There were also some reports of application of $\mathrm{ZnO}$ NRs in different semiconductor heterostructures used for LED construction, i.e. work [32] presents a LED based on $n$-ZnO NRs $/ p$-Si heterojunction. ZnO nanorods were grown on $p$-type Si substrates employing an easy lowtemperature aqueous solution method. Spaces between NRs were filled with high-molecular-weight polymers. A typical EL spectrum of such an $n-\mathrm{ZnO} / p$-Si heterojunction under forward bias was composed of a ultraviolet emission centered at $387 \mathrm{~nm}$ and a broad green band at $535 \mathrm{~nm}$, consistent with the photoluminescence (PL) spectrum. Unfortunately, the obtained intensities and spectral ranges were not satisfactory.

A very interesting direction of research is in the area of hybrid structures, in which ZnO NRs are combined with the $p$-type organic material. The first work in this field shows EL from the structure $\mathrm{ZnO} \mathrm{NRs} /$ poly(3,4-ethylene-dioxythiophene)(PEDOT) /poly(styrenesulfonate)PSS [33]. The ZnO NRs were grown in a low-temperature process from aqueous solution and additionally encapsulated in a thin polystyrene film deposited from high-molecular-weight solutions. This configuration is mechanically very robust. The nearvertical orientation allows use of sandwich-like contacts, which can easily be patterned. Light emission was obtained in the near-UV region (low intensity of $\mathrm{ZnO}$ excitonic luminescence) and a stronger emission covering the entire visible area up to the near-infrared. Unfortunately, the structure showed stability for only an hour. This is a main problem in many applications of organic semiconductors, which are to be solved by introducing coating layers.

Better time stability can be achieved by tightly closing the structure, e.g. reference [34] presents an LED consisting of $\mathrm{SnO}_{2} / \mathrm{ZnO} / \mathrm{PEDOT}$ structures with an internal polystyrene insulator layer. Moreover, as-grown films show a broad electroluminescence band over the visible spectrum, but annealing at quite low temperature of $300^{\circ} \mathrm{C}$ increases the emission and strongly raises the excitonic part of emission. The complete processing procedure was compatible with large-area fabrication on flexible substrates.

In 2008, the possibility of creating a LED based on $\mathrm{ZnO}$ NRs (grown from aqueous solution) in junction with poly(3-methylthiophene (PMT) was presented [35]. The typical EL spectra obtained from this heterostructure device under forward bias show a strong ultraviolet peak and a weak visible emission. The emission of the heterostructure device is much stronger than that of the ZnO-only, however, time stability continues to be a significant problem.

Another and very interesting approach from the standpoint of physics were investigations related to single NRs. In 2006, a novel technique was presented for reliable electrical injection into single semiconductor NRs for LEDs [36]. The first demonstration of this technique was constructing the first $\mathrm{ZnO}$ single-NR LED. The device exhibits broad sub-bandgap emission at room temperature. This is a very interesting approach; however, due to the complexity of this technique and the necessity to use a negative electron-beam resist and direct electron-beam patterning (which is associated with very high costs) the commercial use of this approach is currently excluded.

\subsection{Lasers}

Similarly as in the case of LEDs, single-crystalline semiconductor NRs have long been considered an excellent candidate for achieving laser emission, for example, 
to realize cost effective Fabry-Perot (FP) type lasers, because of the optical feedbacks provided by the naturally formed flat facets in the ends of NRs.

Already in 2001, laser action in the UV range was demonstrated from a matrix of well-oriented $\mathrm{ZnO}$ NRs at room temperature [37]. The $\mathrm{ZnO}$ NRs were grown on sapphire substrates using a simple vapor transport and condensation process. ZnO NRs form natural laser cavities with diameters varying from 20 to $150 \mathrm{~nm}$ and lengths up to $10 \mu \mathrm{m}$. Under optical excitation, surfaceemitting lasing action was observed at $385 \mathrm{~nm}$, with an emission linewidth less than $0.3 \mathrm{~nm}$. Optical pumping with a wavelength of $266 \mathrm{~nm}$ was used, but high powers were needed for the lasing action (a threshold of $\left.40 \mathrm{~kW} / \mathrm{cm}^{2}\right)$.

In 2004, demonstrated were operating random lasers based on $\mathrm{ZnO} \mathrm{NR}$ arrays embedded in the $\mathrm{ZnO}$ epilayers, which consist of a thick $\mathrm{MgO}$ buffer layer and a $\mathrm{ZnO}$ thin film [38]. The presence of $\mathrm{ZnO}$ epilayers increases the optical gain so that random lasing can be sustained. Under $355 \mathrm{~nm}$ optical excitation at room temperature, sharp lasing peaks at around $390 \mathrm{~nm}$ with a linewidth less than $0.4 \mathrm{~nm}$ were observed in all directions. The dependence of the lasing threshold intensity on the excitation area was in good agreement with the random laser theory [39]. We thus claim that such emission in $\mathrm{ZnO}$ NRs arrays was verified.

Finally, in 2011 the fabrication of electrically pumped $\mathrm{ZnO} \mathrm{NR}$ diode lasers using $p$-type Sb-doped $\mathrm{ZnO}$ NRs and $n$-type $\mathrm{ZnO}$ film was reported [40]. FP-type UV lasing was demonstrated at room temperature with good stability.

Of course, the presented results require further optimization work, i.e. the top contact with the $p$-type NR might be engineered to offer both good optical transparency and low electrical resistivity; this is, however, a very important step to be solved for the use of $\mathrm{ZnO} \mathrm{NRs}$ in commercial light emission devices.

\section{Light detection applications}

$\mathrm{ZnO} \mathrm{NRs}$ are an example of nanostructured materials which have attracted much attention because of their massive surface area to volume ratio, their high sensitivity to adsorbed molecules on their surfaces and their good electric transport features. ZnO NRs have shown great promise as UV sensors because of their wide band gap, visible light blindness (in case of high-quality NRs), low-cost and ease of nanostructure fabrication. However, an essential hindrance to $\mathrm{ZnO}$ single NR UV sensors is the very low photo response current due to the small size of individual NRs and chemical processes on the surface which in the case of nanorods play a key role.

\subsection{Detectors on a single NR}

The first reports on the use $\mathrm{ZnO} \mathrm{NRs}$ as light (UV) detecting elements were published in 2002. The possibility of creating highly sensitive NR switches by using the photoconductive properties of individual semiconductor NRs [41] were demonstrated. Individual $\mathrm{ZnO}$
NRs were dispersed directly on pre-fabricated gold electrodes. The conductivity of the $\mathrm{ZnO} \mathrm{NRs}$ is extremely sensitive to ultraviolet light exposure. The light-induced conductivity increase allows us to reversibly switch the NRs between off-state (without UV illumination) and on-state (under UV illumination). The reaction mechanism was connected with adsorption and desorption of oxygen from air. Next, in 2005 there was report on the photoresponsive characteristics of single $\mathrm{ZnO}$ NRs grown by site-selective MBE [42]. These NRs had a relatively fast photoresponse and showed electrical transport dominated by bulk conduction. In 2007, $\mathrm{ZnO}$ single NR visible-blind UV photodetectors with internal photoconductive gain as high as $G \approx 10^{8}$ were fabricated and characterized [43]. The photoconduction mechanism in these devices was clarified by means of time-resolved measurements spanning a wide temporal domain, from $10^{-9}$ to $10^{2} \mathrm{~s}$, revealing the coexistence of fast and slow components of the carrier relaxation dynamics. The extremely high photoconductive gain was attributed to the presence of oxygen-related hole-trap states at the NR surface, which prevents carrier recombination and prolongs the photocarrier lifetime, as evidenced by the sensitivity of the photocurrent to ambient conditions.

In the following year (2006), the possibility of engineering low-power photodetectors by employing individual $\mathrm{Cu}$-doped $\mathrm{ZnO}$ NRs was suggested [44]. Since the $\mathrm{Cu}$ centers are optically active in $\mathrm{ZnO}$, use of $\mathrm{Cu}$ dramatically enhances the photosensitivity levels of the NRs to both UV and visible light as a result of avalanche photomultiplication. The paper was more a presentation of the possibility of the use of $\mathrm{Cu}$-doped NRs than a real presentation of a device, nevertheless the results were very promising.

In 2009, the first single crossed ZnO NR UV photosensor was demonstrated [45]. An in situ lift-out technique was employed to fabricate this photosensor based on selfassembled crossed NRs. The photoresponse suggested that they can be regarded as candidates for optoelectronic devices and may be used for UV detectors. The poor sensitivity and necessity of use of an focused ion beam (FIB) causes that this approach is not attractive for industrial application.

The devices on individual nanostructures generally require sophisticated processing methods, which makes their commercial applications extremely difficult. In this respect, the use of whole matrices of nanostructures, even with the loss of sensitivity or electrical parameters, is much more promising.

\subsection{Detectors on NRs matrices}

The first paper describing the behavior of a $\mathrm{ZnO} \mathrm{NRs}$ matrix under UV illumination was published in 2004 [46]. In summary, the possible scenario of the photocurrent of $\mathrm{ZnO} \mathrm{NRs}$ was discussed from the point of adsorption and desorption of the water molecules giving the hydroxyl group to the oxygen defect sites with the diffusion process through the ZnO NRs. 
In 2006, using the bottom-up approach a UV photodiode, consisting of heterojunction of $n$-type $\mathrm{ZnO} \mathrm{NRs}$ and $p$-type silicon was demonstrated [47]. The performance of UV photodiodes could be enhanced due to the good UV responsivity and larger excitation area to volume ratio of $\mathrm{ZnO}$ NRs. According to experimental results, the current-voltage characteristics of the device showed the typical rectifying behavior of heterojunctions, and the photodiode exhibited a response of $\approx 0.07 \mathrm{~A} / \mathrm{W}$ for $\mathrm{UV}$ light $(365 \mathrm{~nm})$ under a $20 \mathrm{~V}$ reverse bias. The sensitivity to UV was rather poor and this approach also required use of a quite large reverse bias, but it was the first prototype of UV photodiode using $\mathrm{ZnO}$ NRs.

In 2008, a method was proposed to fabricate $\mathrm{ZnO}$ bridging NR structure exhibiting high performance in UV detection [48]. This method uses a single-step CVD process, in which the electrodes and sensing elements are fabricated at the same time. The electrodes are formed by the thick $\mathrm{ZnO}$ layers covering the Au-catalyst-patterned areas on the substrate, and the sensing elements consist of the ultra-long $\mathrm{ZnO}$ NRs bridging the electrodes. The fabricated nanobridge device shows fast response to UV illumination in ambient air and also the highest sensitivity among the $\mathrm{ZnO}$ NRs array. A similar sensitivity for the ZnO NRs matrix was reported only once in subsequent years [49]. The detector described in this work was characterized by a slightly lower sensitivity, but a simpler production technology. The basis of the detector was a matrix of nanorods produced on quartz substrate by extremely simple and fast growth from water solution, and the resultant nanorods were defect-free, which was the key to their high sensitivity. Detection edge was close to $400 \mathrm{~nm}$ wavelength. Importantly, annealing and/or chemical treatment was not necessary before reuse. Detection was based on monitoring the sample resistance changes which was associated with the adsorption and desorption processes of hydroxyl groups on the surface of the nanorods. The electric response was scaling with light intensity. High sensitivity and extremely simple manufacturing technology make this detector very attractive for potential applications.

In 2009, a few papers were published on UV detectors based on ZnO NRs matrices produced by MOCVD or arc discharge method [50, 51]. However, the obtained sensitivities were not groundbreaking. In the same years, paper [52] was published with photoresponse measurements of $\mathrm{ZnO}$ NRs under different relative humidity to study the surface effects of oxygen and water. The proposed model can help to better understand gas desorption and adsorption processes on the surface of metal oxide semiconductors, which play a central role in photodetection and gas sensing.

In 2010, a highly interesting work was published about well-oriented $\mathrm{ZnO} \mathrm{NRs}$ distributed onto the surface of $\mathrm{ZnO}$ nanofibers. The matrix was produced by the combination of electrospinning and hydrothermal reaction [53]. Both the current and the UV responsiveness were enhanced significantly after grow- ing $\mathrm{ZnO} \mathrm{NRs}$ onto the surface of $\mathrm{ZnO}$ nanofiber. After surface functionalization with a layer of N719 (di-tetrabutylammonium cis-bis(isothiocyanato)bis $\left(2,2^{\prime}\right.$ bipyridyl-4,4'-dicarboxylato)ruthenium(II)) dye molecules, the current of the $\mathrm{ZnO} \mathrm{NR} / \mathrm{ZnO}$ nanofiber device could also be regulated by visible light.

In 2011, a bottom-up approach to fabricating macroscopic integrated $\mathrm{ZnO} \mathrm{NR}$ UV sensors was demonstrated [54]. Macroscopic multi-NR-based UV sensors were fabricated by transferring vertically aligned $\mathrm{ZnO}$ NRs to a parallel-aligned layer on a polydimethylsiloxane (PDMS) surface, followed by integration with electrodes patterned on rigid glass and flexible PET substrates. This multi-NR sensor design saved all the advantages of single-NR devices, including high on/off current ratio and fast response and recovery times.

In 2012, another approach was reported - high quality $\mathrm{ZnO}$ NRs were grown on $p$-type Si (111) substrates via microwave-assisted chemical solution methods [55]. The unbiased operation mode of this UV detector offered excellent stability over time. The high sensitivity and faster response and recovery times of this $\mathrm{ZnO} \mathrm{NR}$ array $/ p$-Si UV detector make this device a promising self-powered UV detector.

A few years later in very similar approach, a photoresistor based on $\mathrm{ZnO} \mathrm{NRs}$ and silicon substrate (very low - $p$-type) was presented [56]. The wavelength detection range is between 400 and $1100 \mathrm{~nm}$ which reflects light absorption by the silicon partner of the junction. Importantly, post-illumination annealing or chemical treatment is not necessary before reuse of the detector. The absorption of light near the junction of two materials causes generation of electron-hole pairs which were separated by the band bending in the depletion layer. The band bending caused the flow of electrons to $\mathrm{ZnO}$ NRs (slightly $n$-type) which were not actively involved in the photocurrent. The holes gathered on the Si side, thus, creating an active conducting channel. High sensitivity and the extremely simple manufacturing technology made this detector very attractive for potential applications. The poor relationship between the response and the light intensity enabled usage as an optical switch.

\section{ZnO NRs in PV applications}

A wide energy band gap in the UV area prevents direct absorption of visible light while retaining high crystallographic quality, which is necessary for effective separation of carriers. Despite this, the advantages of the NR geometry can improve the efficiency of many types of photocells, dye-sensitized solar cells (DSSC), perovskite, organic, or even silicon based.

\subsection{Dye-sensitized solar cells}

Among various applications, the utilization of $\mathrm{ZnO}$ nanostructures as a photo-electrode for DSSCs has received a considerable attention and interest recently due to their compatibility with the commonly used $\mathrm{TiO}_{2}$ materials [57]. $\mathrm{ZnO}$ shows higher electronic mobility and 
a similar energy level of the conduction band to $\mathrm{TiO}_{2}$ which make $\mathrm{ZnO}$ suitable for use as a photo-electrode material for the fabrication of efficient DSSCs.

The NR dye-sensitized solar cell is an exciting variant of excitonic photovoltaic devices. As an ordered topology that increases the rate of electron transport, a NR electrode may provide a means to improve the quantum efficiency of DSSCs. Raising the efficiency of the PV cell to a competitive level depends on achieving higher dye loadings through an increase in surface area.

The first demonstration of the possibility of using NRs in DSSC instead of metal nanoparticles (NPs) was published in 2005 [58]. The idea of integrating nanorods with DSSC was under development for many years. The first work with the use of $\mathrm{ZnO} \mathrm{NRs}$ appeared in 2006 [59]. $\mathrm{ZnO} \mathrm{NRs}$ were used as a photo-electrode. Typical solar cell photocurrent was $1.3 \mathrm{~mA} / \mathrm{cm}^{2}$, photovoltage $0.7 \mathrm{~V}$, fill factor - 0.35-0.40 and overall efficiencies were $0.3 \%$. Electron transport through the NRs was not constrained by the NR dimensions. ZnO NR-based DSSC were prepared by adsorbing N719 dye onto the NR surface.

In 2008, an article was published with studies of the interface capacitance of a DSSC made from chemically prepared $\mathrm{ZnO}$ NRs by time-resolved photocurrent and electrical impedance measurements [60]. While the electrical response was in good agreement with the space charge capacitance theory, the variation of the measured capacitance with the applied bias was found to deviate significantly from the simple electrostatic model. This is in strong contrast to the predictions of the electrostatic theory that is usually applied to model the space charge capacitance. Even the numerical solution of the full electrostatic problem in quasi $3 \mathrm{D}$ did not provide a good approximation. This work suggested the need for further investigations to better understand the quasi static charge distribution in the $\mathrm{ZnO} \mathrm{NR}$ assemblies prepared from solution.

In the same year, a work appeared with a comparison of the performance of DSSC based on $\mathrm{ZnO}$ NRs prepared by hydrothermal and vapor-deposition methods [61]. DSSCs based on hydrothermally grown rods exhibit higher power conversion efficiency, which can be attributed to the higher dye adsorption. The photovoltaic performance exhibits a complex relationship to the presence of surface $\mathrm{OH}$ groups and defect emissions, and optimal annealing conditions are strongly dependent on the growth method used. Efficiency of $0.22 \%$ was obtained for both as-grown hydrothermally grown NRs and vapor deposited nanorods annealed in oxygen at $200^{\circ} \mathrm{C}$.

Research on conjunction $\mathrm{ZnO}$ NRs with this sensitizing dye has been under further investigation. In 2009, a paper was published with results on vertically aligned ZnO NR arrays coated with gold nanoparticles used in Schottky barrier PV cells [62]. After incorporation of N719 sensitizing dye, the open circuit voltage increased to $0.63 \mathrm{~V}$ from $0.5 \mathrm{~V}$ being measured for dye-sensitized solar cells based on the bare ZnO NRs. The efficiency of the gold-coated $\mathrm{ZnO} \mathrm{NR}$ dye-sensitized solar cells was thus increased from $0.7 \%$ to $1.2 \%$. In the same year there was another paper on well-crystallized hexagonal-shaped ZnO NRs used as photo-anode materials, also in conjunction with N719, to fabricate the DSSCs which exhibited an overall light to conversion efficiency of $1.86 \%$ with a very high fill factor of $74.4 \%$, short-circuit current of $3.41 \mathrm{~mA} / \mathrm{cm}^{2}$ and open-circuit voltage of $0.73 \mathrm{~V}$ [63].

In 2010, results were presented on DSSC based on $\mathrm{ZnO}$ NRs and N719, fabricated and modified through the addition of $\mathrm{Au}$ NPs [64]. The high quality as-synthesized $\mathrm{ZnO} \mathrm{NRs}$ were well-dispersed and led to a high cell efficiency of $5.2 \%$. Cells with $\mathrm{Au}$ NPs resulted in lower efficiency $(2.5 \%)$. The thick layer of Au NPs aggregation may have led to distortion of the plasmonic effect. Also, the addition of $\mathrm{Au}$ NPs effectively decreased the surface area of $\mathrm{ZnO}$ NRs with direct contact to the dye molecules, resulting in a lower amount of adhered dye molecules to convert sunlight. The electrons generated by the photo-absorption through the thickly aggregated $\mathrm{Au}$ NPs layer may have a lower injection rate to $\mathrm{ZnO}$ NRs as compared to those absorbed by the dye.

The last report on DSSC contains description of very interesting structures in the form of a nanoforest of high density, long branched treelike multigeneration hierarchical crystalline $\mathrm{ZnO} \mathrm{NR}$ photoanodes obtained by a selective hierarchical growth sequence [65]. The shortcircuit current density and overall light conversion efficiency of the branched ZnO NR DSSCs were almost five times higher than the efficiency of standard vertical $\mathrm{ZnO}$ NRs and reached $2.63 \%$. The efficiency increase is due to the increased surface area enabling higher dye loading and light harvesting, as well as to reduced charge recombination through direct conduction along the crystalline $\mathrm{ZnO}$ nanotree branches.

Despite these interesting results, the use of $\mathrm{ZnO} \mathrm{NRs}$ in DSSC is currently undergoing a period of stagnation.

\subsection{Perovskite-based PV cells}

Like in the case of DSSC cells, the advantages of $\mathrm{ZnO}$ NRs can be used in perovskite solar cell (PSC) technology, i.e. higher electronic mobility and similar energy level of the conduction band to $\mathrm{TiO}_{2}$. Already in 2014 a work was published on high-efficiency ZnO NR-based perovskite solar cell with power conversion efficiency (PCE) of over $11 \%$ with short-circuit current density $J_{S C}$ of $20.08 \mathrm{~mA} / \mathrm{cm}^{2}$, open-circuit voltage $\left(V_{O C}\right)$ of $991 \mathrm{mV}$ and fill factor of 0.56 [66]. The ZnO NR-based PSC showed almost ideal external quantum efficiency (EQE) spectral shape with excellent matching of the calculated $J_{S C}$ with the measured $J_{S C}$. Compared to a limited detection in charge collection due to the slow charge collection rate and low absorbed photon-to-current conversation efficiency for the $\mathrm{TiO}_{2}$ NR-based PSC, the $\mathrm{ZnO} \mathrm{NR}$ system showed fast saturation in charge collection, which indicates that $\mathrm{ZnO}$ NRs are an effective charge collection system in $\mathrm{CH}_{3} \mathrm{NH}_{3} \mathrm{PbI}_{3}$ based perovskite solar cells. 
Two years later, a work was presented on $\mathrm{ZnO}$ NRs perovskite-based solar cells on rigid and on flexible substrates [67]. Optimizing the $\mathrm{ZnO} \mathrm{NRs}$ growth conditions enabled achievement of a PCE of $9.06 \%$ with a current density of $21.5 \mathrm{~mA} / \mathrm{cm}^{2}$. Moreover, flexible $\mathrm{ZnO} \mathrm{NRs}$ PSCs were fabricated, demonstrating excellent stability over 75 bending cycles with PCE of $6.4 \%$. This investigation shows that $\mathrm{ZnO} \mathrm{NRs}$ can be used as an efficient alternative to low temperature photoanode.

Despite the considerably higher efficiency of inorganicorganic metal hybrid PSCs, electron transport was still a challenging issue. In 2017, a report was published on the use of $\mathrm{ZnO}$ NRs prepared by hydrothermal selfassembly as the electron transport layer in PSCs [68]. The efficiency was significantly enhanced by passivating the interfacial defects through atomic layer deposition (ALD) of $\mathrm{Al}_{2} \mathrm{O}_{3}$ monolayers on the $\mathrm{ZnO}$ NRs. By employing the $\mathrm{Al}_{2} \mathrm{O}_{3}$, the average power conversion efficiency of methylammonium lead iodide PSCs was increased from $10.33 \%$ to $15.06 \%$, and the highest efficiency obtained was $16.08 \%$. The authors suggested that the passivation of defects using the ALD of monolayers might provide a new pathway for the improvement of all types of PSCs. The results received are very promising and achieving higher efficiencies in such cells is only matter of time.

\subsection{Thin film PV cells (based on $\mathrm{Cd}$ and $\mathrm{Cu}$ )}

Very interesting results were also obtained with the application of $\mathrm{ZnO} \mathrm{NRs}$ in Cd-based photovoltaic cells. In 2005, a work was published on an ETA (extra thin absorber) solar cell fabricated from an electron-accepting layer of free standing $\mathrm{ZnO} \mathrm{NRs}$, a light-absorbing layer of CdSe, and a hole-accepting layer of copper thiocyanate which fills vacuities between the $\mathrm{ZnO} / \mathrm{CdSe}$ NRs [69]. The $\mathrm{ZnO}$ distracts photons within the light-absorbing layer, increasing the chance for light absorption. Meanwhile, the low thickness of the CdSe layer facilities transfer of photogenerated electrons to $\mathrm{ZnO}$. This nanostructure creates an output current that is up to 50 times greater than in a solar cell made of flat, dense substrate material. The total efficiency reached $2 \%$.

In 2007, a quantum-dot sensitized NR solar cell based on photosensitization of $\mathrm{ZnO} \mathrm{NRs}$ with CdSe quantum dots was demonstrated [70]. Photocurrent was generated from visible light by the excitation of electron hole pairs in the CdSe quantum dots. The electrons were injected across the quantum dot-NR interface into the ZnO. Further improvement on the efficiency and stability of these devices would require development of an optimal hole transport medium for this architecture. The received efficiency below $1 \%$ is much lower than theoretically predicted efficiencies.

In 2009, a work was presented on $\mathrm{ZnO} / \mathrm{CdSe}$ core-shell NR array films used as the photo anodes in solar cells [71]. A power conversion efficiency of $0.34 \%$, a photocurrent density of $3.10 \mathrm{~mA} / \mathrm{cm}^{2}$ and an open circuit potential of
$0.43 \mathrm{~V}$ were achieved under optimum parameters. Although the power-conversion efficiency is not sufficiently high in this preliminary work, using CdSe nanocrystals as sensitizers for the $\mathrm{ZnO}$ solar cells is quite encouraging by reducing the thickness of the CdSe shell and tuning the size of the CdSe nanocrystals in order to improve the light absorption properties of the electrodes. Despite the efficiency issue, this study gives some insights into the fundamental mechanisms. Unfortunately, this did not translate into further improvement of results in this configuration.

\subsection{Organic based PV cells}

Another direction for the development of photovoltaic cells is a conjunction of $\mathrm{ZnO}$ NRs and organic semiconductors. The first paper in this field was published in 2006 and described a photovoltaic device based on NR structure with poly(3-hexylthiophene-2,5-diyl) (P3HT) polymer and showed a power conversion efficiency over four times greater than that for a similar device based on NPs [72]. The best ZnO NR:P3HT device using the molecular interface layer yields a short circuit current density of $2 \mathrm{~mA} / \mathrm{cm}^{2}$ under $\mathrm{AM} 1.5$ illumination $\left(100 \mathrm{~mW} / \mathrm{cm}^{2}\right)$ resulting in a power conversion efficiency of $0.2 \%$. The low $V_{O C}$ can be attributed partly to shunt losses due to imperfections in the dense $\mathrm{ZnO}$ layer, and the low $J_{S C}$ to low charge separation efficiency due to the large film pore sizes $(\approx 100 \mathrm{~nm})$ relative to the $\mathrm{P} 3 \mathrm{HT}$ exciton diffusion length.

In 2007, a paper appeared on the effect of polymer processing on $\mathrm{P} 3 \mathrm{HT} / \mathrm{ZnO} \mathrm{NR}$ photovoltaic device performance [73]. The best device was characterized by a PCE of $0.28 \%$, a $V_{O C}$ of $440 \mathrm{mV}$, a $J_{S C}$ of $1.33 \mathrm{~mA} / \mathrm{cm}^{2}$, and a fill factor of $48 \%$. These data clearly show that the optimization of solvent selection and polymer processing can significantly improve the performance of $\mathrm{P} 3 \mathrm{HT} / \mathrm{ZnO}$ NR composite devices.

In the same year, the performance of the hybrid photovoltaic devices was improved as the average length of the $\mathrm{ZnO} \mathrm{NR}$ was increased [74]. From the dependence of the photovoltaic performance on the $\mathrm{ZnO}$ NR length and the organic layer thickness, it was clearly demonstrated that the introduction of the direct transport channel to the electrode could enhance the performance of photovoltaic devices with thick active layers. Such thick active layers could be advantageous especially when polymers with small extinction coefficients and broad absorption spectra are used for the absorption layers. The fill factor of the devices increased from $38 \%$ to $50 \%$ when an array of the ZnO NRs was introduced, which directly contributed to the improvement of the power conversion efficiencies up to $2.7 \%$.

In the next year, another version of hybrid flexible organic PV cells was demonstrated. ZnO NRs were grown on transparent and conductive single-walled carbon nanotube (CNT) thin films [75]. The structure was created by directly growing ZnO NRs from solution on the single-walled CNT electrodes and spin coating 
the $\mathrm{P} 3 \mathrm{HT}$ polymer. A maximum $\mathrm{PCE}$ of $\approx 0.6 \%$ was achieved. There was observed enhancement of the response in the blue-near UV region through absorption by the $\mathrm{ZnO} \mathrm{NRs}$.

Very interesting results were published on the use of $\mathrm{ZnO} \mathrm{NRs}$ grown on reduced graphene oxide (rGO) [76]. This structure was used to fabricate inorganic-organic hybrid solar cells with a layered structure of quartz/rGO/ZnO $\mathrm{NR} /$ $\mathrm{P} 3 \mathrm{HT} /$ poly(3,4-ethylenedioxythiophene) (PEDTOT): poly(styrenesulfonate) (PSS)/Au. The observed PCE of $0.31 \%$ was higher than that reported in previous solar cells by using graphene films as electrodes.

In 2010, a structure was presented using P3HT:phenylC61-butyric acid methyl ester (PCBM) as an active polymer blend, which was found to be compatible with a prepared ITO substrate base [77]. The structure ITO/ZnO film/ZnO NR/P3HT: PCBM/Ag showed a relatively high efficiency of $2.44 \%$.

Also in 2010 a work was published presenting hybrid bulk heterojunction PV cells based on $\mathrm{ZnO}$ nanorods blended with P3HT [78]. Tetra(4carboxyphenyl)porphyrin (TCPP) molecules were grafted onto the surface of $\mathrm{ZnO} \mathrm{NRs}$ to enlarge the absorption spectrum of the blend. However, the overall photocurrent of the device decreases gradually with TCPP concentration at the $\mathrm{ZnO} \mathrm{NR}$ surface. TCPP grafting is beneficial for additional photocurrent generation in the $\mathrm{P} 3 \mathrm{HT}: \mathrm{ZnO}$ blend but introduces strong modification of the blend morphology and charge carrier dynamics at the $\mathrm{P} 3 \mathrm{HT} / \mathrm{ZnO}$ interface, which finally reduces the overall photocurrent generation.

In the next year a method was shown for the enhancement in photovoltaic performance of hybrid solar cells constructed from ZnO NRs and P3HT by Li incorporation to $\mathrm{ZnO}$ crystal [79]. The oxygen-enrichment of the $\mathrm{ZnO}$ surface caused by Li doping, observed by red PL emission, yields the effective charge transfer at the interface. This leads to the increase of $J_{S C}$. The obtained improvement of $V_{O C}$ was obtained. However, further LiZn leads to increased reverse current densities of minority carriers decreasing $V_{O C}$ after the maximum value at 5 at. $\%$ incorporation. The maximum power conversion efficiency of $0.37 \%$ was obtained at 5 at.\% doping.

In recent years, work in these areas has been continued, but no breakthroughs have occurred.

\subsection{Silicon based PV cells}

One of the most promising applications of $\mathrm{ZnO} \mathrm{NRs}$ is their inclusion in the architecture of silicon-based $\mathrm{PV}$ cells. In recent years, there has been many works on this subject, and the results are extremely interesting. The first advantages were connected with antireflectance properties of an NRs array. In 2012 a paper was published on the growth of $\mathrm{ZnO}$ NRs on a $\mathrm{ZnO} /$ textured $c$-Si photovoltaic device through the hydrothermal method [80]. The reflectance spectra and $I-V$ characteristics indicated that the $\mathrm{ZnO}$ /textured $c$ Si photovoltaic device with $\mathrm{ZnO}$ NRs had the lowest reflectance among the tested devices, especially in the range of UV and green light (350 nm to $590 \mathrm{~nm}$ ). Compared to $\mathrm{SiNx}$ /textured $c$-Si and $\mathrm{ZnO} /$ textured $c$-Si photovoltaic devices, the proposed device exhibited PCE improvements of around $7 \%$ and $6.3 \%$, respectively.

In the next year, a novel approach was introduced of using transparent conducting oxide (TCO) NR arrays as a replacement for conventional textured TCO layers in the configuration of silicon $p-i-n$ solar cells [81]. Enhanced PCE and improved $I(V)$-characteristics were shown from $5.9 \%$ to $6.7 \%$.

In the same year, the use of ZnO NRs was demonstrated as an anti-reflecting (AR) coating on planar and textured, industrial scale Si solar cells [82]. For planar and textured single-crystalline Si solar cells, photovoltaic efficiencies of $7.5 \%$ and $11 \%$ have been obtained without ARs, while these values were improved to $10 \%$ and $12.7 \%$ through the growth of ZnO NRs, respectively. An almost one order of magnitude improvement in the minority carrier lifetime indicated the passivation effect of $\mathrm{ZnO}$ NRs.

A similar solution was under further investigation. In 2016, a multi-crystalline solar cell with two functional layers - $\mathrm{ZnO}$ nanostructures and an $\mathrm{Al}_{2} \mathrm{O}_{3}$ spacer layer was demonstrated [83]. Results show that the $\mathrm{ZnO}$ nanostructures synthesized from the seed layer with optimized thickness exhibit excellent photon harvesting ability in the visible light range, leading to an increase in short circuit current of the PV cells. Eventually, a maximized conversion efficiency of $15.8 \%$ was achieved by the multi-crystalline solar cell with the optimized $\mathrm{Al}_{2} \mathrm{O}_{3} / \mathrm{ZnO}$ nanostructures stack, which exhibit comparable performance to the previously reported singlecrystalline $\mathrm{Si}$ cell based on $\mathrm{ZnO}$ nanostructures with a highest PCE of $16.0 \%$.

In 2014, a first paper was presented about ZnO NRs used not only as an AR layer, but also as a junction partner with Si in PV cell [84]. The structure consists of $p$-type Si substrate, $\mathrm{ZnO} \mathrm{NR}$ as $n$-type partner and AZO (Al doped $\mathrm{ZnO}$ ) film (grown at a low deposition temperature in the ALD process). A wide spectral range of the absorption (from $350 \mathrm{~nm}$ to $1200 \mathrm{~nm}$ ) was observed. The wide working spectrum and the good junction quality led to $3.6 \%$ quantum efficiency. The investigated PV structures are very cheap and easily constructed. Of course, NRs 3D morphology also leads to increased light trapping. In this work, the authors used a new method for the growth of $\mathrm{ZnO} \mathrm{NRs}$, which produces very high quality NRs despite the very fast (several minutes) and low-temperature growth process [19] see Figs. 1 and 2.

The same group published another article in the following year - by minor changes in the technology they were able to obtain almost $11 \%$ of efficiency [85]. The only change was filling the spaces between NRs with $\mathrm{ZnO}$ deposited by the ALD method (this method was used in the previous approach to grow an AZO layer on the $\mathrm{ZnO}$ nanorods). Thanks to this the junction area was more continuous and an improvement in efficiency was 

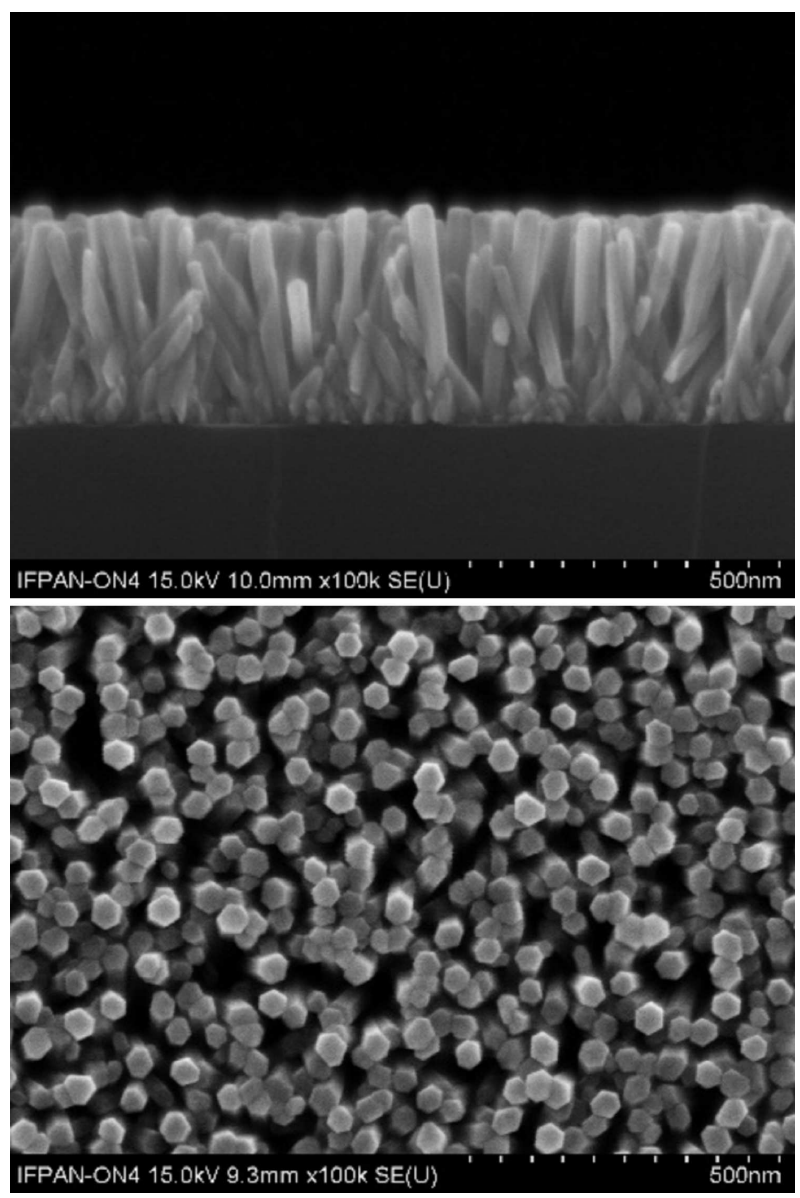

Fig. 1. Scanning electron microscopy images of $\mathrm{ZnO}$ NRs on silicon substrate.

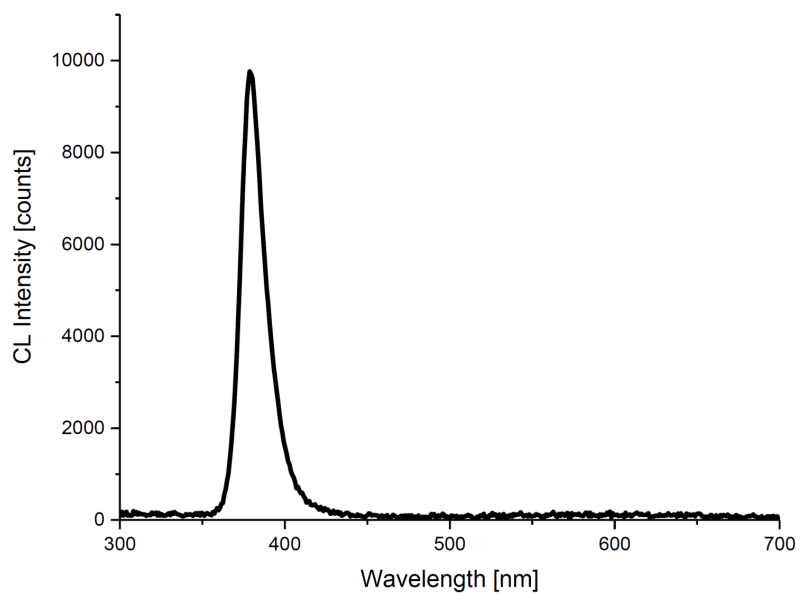

Fig. 2. Room-temperature cathodoluminescence spectra of $\mathrm{ZnO}$ NRs on silicon substrate.

obtained. Two years later, the same group published another important improvement — the $\mathrm{ZnO}$ layer, which previously has been grown on NRs (between NRs and AZO layer) was changed to a $\mathrm{ZnMgO}$ layer (also grown by the ALD method) [86]. Due to this simple change, the efficiency was increased to $14 \%$, and this result was obtained with point contact and without optimization of the thickness of silicon substrate. The results presented there indicate that the $\mathrm{ZnO} / \mathrm{Si}$ heterojunction solar cell can potentially be a less expensive high-efficiency structure that can be fabricated by an environmentally friendly method. What is important, all technologies used in this approach are very inexpensive and easy scalable to industrial size.

There were further works on a similar structures $(p$ type $\mathrm{Si}$ and $n$-type $\mathrm{ZnO}-\mathrm{NRs}$ ), that focused on the application of metallic NPs to use plasmonic effects to support the process of light absorption and separation of carriers [87-89]. However, the final results did not show higher efficiencies than previously reported for the best structures of this type.

\section{Photocatalytic applications}

Photocatalysis is a light-induced catalytic process whereby photogenerated electron-hole pairs in a semiconductor undergo redox reactions with molecules adsorbed onto the surface, thereby breaking them into smaller fragments. Photocatalysis with metal-oxidesemiconductor nanostructures has been an area of intense research over recent years with $\mathrm{TiO}_{2}[90]$. Optical absorption in the deep ultraviolet region and low photoefficiency [91] are factors that hold the wide scale use of $\mathrm{TiO}_{2}$ for photocatalytic activities under sunlight. ZnO, with a high surface reactivity owing to a large number of native defect sites coming from oxygen nonstoichiometry, has found to be an efficient photocatalyst material. $\mathrm{ZnO}$ exhibits comparatively higher reaction and mineralization rates [92]. Surface area and surface defects play an important role in the photocatalytic activity of metaloxide nanostructures, as the contaminant molecules need to be adsorbed onto the photocatalytic surface for the redox reactions to occur. The higher the effective surface area, the higher the adsorption of target molecules will be, leading to better photocatalytic activity. One dimensional nanostructures, such as NRs, offer a higher surface to volume ratio compared to nanoparticulate coatings on a flat plate. In 2014, important work was published on the effect of aspect ratio and surface defects on the photocatalytic activity of $\mathrm{ZnO}$ NRs [93]. The studies showed that as-synthesized ZnO NRs have good photocatalytic performance (degradation of methylene blue (MB)), and the photocatalytic activity increased with increasing aspect ratio. The high aspect ratio of $\mathrm{ZnO}$ NRs exhibit a high level of surface defects, which is the reason for the high photocatalytic performance. Photocatalytic activity comparable to that of doped $\mathrm{ZnO}$ was also observed with engineered defects in $\mathrm{ZnO}$ crystals achieved by fast crystallization during synthesis of the NPs [94]. Comparative results of photocatalytic degradation studies on $\mathrm{MB}$ with visible light irradiation demonstrated that ZnO NRs are $12-24 \%$ more active than nanostructured films. An enhancement of $8 \%$ in the photocatalytic activity of $\mathrm{ZnO}$ NRs was achieved through creation of oxygen deficient structures using a fast crystallization process achieved by microwave assisted hydrolysis. 
Due to a wide band gap of $3.37 \mathrm{eV}$, poor photon absorption in visible spectra region of $\mathrm{ZnO}$ limits its application as an in visible light photocatalyst. In order to shift the optical absorption of $\mathrm{ZnO}$ into the visible region, one possible approach is to dope transition metal ions into $\mathrm{ZnO}$ photocatalyst. This idea was realized by different dopants, i.e. Co doping [95], La [96], $\mathrm{Ni}$ [97], $\mathrm{Cr}$ [98], $\mathrm{Cu}$ [99], Hg [100] or Ce [101]. In all these examples, doped NRs exhibit higher photocatalytic activity than similar NRs without dopants.

Another interesting approach was based on the combination of $\mathrm{ZnO} \mathrm{NR}$ and graphene (G) sheets. In 2013, a paper was published on the sandwich-like $\mathrm{ZnO} / \mathrm{G} / \mathrm{ZnO}$ heterostructures with much higher photocatalytic activity under UV light irradiation than that of comparable $\mathrm{ZnO} \mathrm{NRs}$, with a photocatalytic degradation rate of $\mathrm{MB}$ three times faster than that of the ZnO NRs [102]. Still, the low efficiency of photocatalytic activity for the visible region was not solved. One year later, a similar approach was presented with sensitization of $\mathrm{ZnO}$ NRs on rGO with CdS NPs on ZnO NRs [103]. This approach helped to achieve an increase in the photocatalytic performance of the synthesized composites toward degradation of $\mathrm{MB}$ in visible light. The idea to sensitize NRs to visible light by adding NPs was presented. For example, in 2011 a paper was published on the use of $\mathrm{CuO}$ NPs to increase photocatalytic performance [104] and in 2014 the use of $\mathrm{Nb}_{2} \mathrm{O}_{5}$ NPs led to excellent photocatalytic performance on the degradation of phenol [105]. Photocatalytic mechanism investigations demonstrated that the degradation of phenol under natural sunlight was mainly via $\mathrm{OH}$ radical oxidation mechanism. The improvement in photocatalytic activity was attributed to enhancement of the sunlight absorbing capability stemming from a good interface connection between two semiconductors with appropriate band structures so that charge transfer could proceed efficiently.

An alternative approach presented in the literature is based on coating the NRs with metallic NPs. The first paper on this solution appeared in 2006. Photodegradation of methyl orange (MO) under $365 \mathrm{~nm}$ irradiation was performed to investigate the photocatalytic activities of the $\mathrm{Au} \mathrm{NPs} / \mathrm{ZnO}$ NRs [106]. Enhancement of the photocatalytic activity for degradation of MO was achieved by loading $\mathrm{Au}$ nanoparticles with sizes smaller than $15 \mathrm{~nm}$. The effect is more distinct as the size of the $\mathrm{Au} \mathrm{NPs}$ is reduced to $5 \mathrm{~nm}$. The charge separation ability of the Au NPs may strongly depend on their sizes, resulting in various photocatalytic activities heterostructures. This may be related to the scattering of the incident irradiation by the Au NPs and the formation of the Schottky barriers at the junction of the ZnO NRs and the $\mathrm{Au} \mathrm{NPs}$. In the following years, similar approaches were presented in the cases of Pt NPS [107] and Ag NPs [108]. In both cases, NPs size and density must be aligned, otherwise the decrease of photocatalytic activity may be observed.

\section{Field emission}

Thin films of nanostructures with high aspect ratio, such as nanotubes and NRs, are considered to be ideal FE electron sources that can emit electrons at low electric field. Among these materials, CNT thin films have received much attention. However, relatively few studies have been carried out on the FE from nanostructured thin films made of other materials such as ZnO NRs. With structural properties similar to CNT, such as a high aspect ratio and stability in vacuum environment, it is possible that $\mathrm{ZnO}$ NRs could have excellent electron emission properties.

In 2003, the possibility to enhance the FE from a tungsten tip with $\mathrm{ZnO}$ NRs was demonstrated. ZnO NRs were grown on a sharp tungsten tip as a FE electron source by a simple and effective vapor-transport method [109]. The results were similar as obtained for CNT.

The first systematic research on $\mathrm{ZnO}$ NRs as independent emitters began in 2002 [110]. In this work vertically well-aligned $\mathrm{ZnO} \mathrm{NRs}$ were grown by the vapor deposition method at a low temperature of $550{ }^{\circ} \mathrm{C}$, using Co as catalyst. The turn-on voltage for the $\mathrm{ZnO}$ NRs was found to be about $6 \mathrm{~V} / \mu \mathrm{m}$ at current density of $0.1 \mu \mathrm{A} / \mathrm{cm}^{2}$. The emission current density from the $\mathrm{ZnO}$ $\mathrm{NRs}$ reached $1 \mathrm{~mA} / \mathrm{cm}^{2}$ at a bias field of $11 \mathrm{~V} / \mu \mathrm{m}$, which could provide sufficient brightness as a field emitter in a flat panel display. Therefore, the well-aligned $\mathrm{ZnO}$ became a research subject concerning the application of a glass-sealed flat panel display in the near future (even though the threshold voltage for FE is still higher than that of CNTs).

In 2003, it was shown that the FE from the randomly oriented $\mathrm{ZnO}$ NRs can be significantly improved by reducing the NRs areal density [111]. It was shown that the same screening effect observed on CNT field emitters also affects the FE from ZnO NRs. Thin films with the lowest areal density of $\mathrm{ZnO}$ NRs showed much better FE characteristics, comparable to those of CNT. The electric field required to obtain the FE current density of $1 \mathrm{~mA} / \mathrm{cm}^{2}$ from a $\mathrm{ZnO} \mathrm{NR}$ thin film with very low areal density was $6.46 \mathrm{~V} / \mu \mathrm{m}$, which is comparable to the result from CNT field emitters.

Similar results were obtained by different groups [112]. The turn-on field of the $\mathrm{ZnO} \mathrm{NRs}$ was about $6.2 \mathrm{~V} / \mu \mathrm{m}$ at a current density of $0.1 \mu \mathrm{A} / \mathrm{cm}^{2}$, and the emission current density reached $1 \mathrm{~mA} / \mathrm{cm}^{2}$ at an applied field of about $15 \mathrm{~V} / \mu \mathrm{m}$.

It is well known that FE mainly depends on tip morphology and the density of NRs. Such good FE properties resulted from the small geometry of $\mathrm{ZnO} \mathrm{NRs}$ and shape engineering. In 2003, well-aligned arrays of $\mathrm{ZnO}$ nanoneedles were fabricated using a simple vapor phase growth [113]. The diameters of the nanoneedle tips are as small as several nanometers, which is highly in favor of the FE. FE measurements using the nanoneedle arrays as a cathode showed emission current density as high as $2.4 \mathrm{~mA} / \mathrm{cm}^{2}$ under the field of $7 \mathrm{~V} / \mu \mathrm{m}$, and a very low turn-on field of $2.4 \mathrm{~V} / \mu \mathrm{m}$. 
Such a high emission current density was connected with the high aspect ratio of the nanoneedles.

The importance of the shape was also confirmed by later studies [114]. Standard ZnO NRs with a diameter of $150 \mathrm{~nm}$ showing poor FE performance were modified (by reducing the tip radius of NRs to $5 \mathrm{~nm}$ ). The second modification was decorating the NRs with small metal NPs. Each of these two approaches produced excellent FE performance, typically turn-on field (the electric field at which the current density reaches $\left.10 \mu \mathrm{A} / \mathrm{cm}^{2}\right)$ as small as $2 \mathrm{~V} / \mu \mathrm{m}$ and current density as large as $1 \mathrm{~mA} / \mathrm{cm}^{2}$. For the validity of the concept of decoration with metal particles, the metal should be stable against oxidation and have a work function smaller than that of the emitting material. The larger the work function of the emitting materials, the more effective the electron subsidy. It was shown that there is a size range within which metal NPs decoration works in enhancing the FE performance of $\mathrm{ZnO}$ nanomaterials.

The influence of metallic NPs has been observed before. In work [115], ZnO NRs synthesized by the vaporliquid-solid growth mechanism with $\mathrm{Cu}$ and $\mathrm{Au}$ as the catalyst were investigated. The $\mathrm{Cu}$-catalyzed $\mathrm{ZnO} \mathrm{NRs}$ with a high-quality wurtzite structure were grown vertically on $p$-type $\mathrm{Si}(100)$ substrate. These ZnO NRs show excellent FE properties with turn-on field of $0.83 \mathrm{~V} / \mathrm{mm}$ and current density of $25 \mu \mathrm{A} / \mathrm{cm}^{2}$. The emitted current density of the $\mathrm{ZnO} \mathrm{NRs}$ is $1.52 \mathrm{~mA} / \mathrm{cm}^{2}$ at a bias field of $8.5 \mathrm{~V} / \mu \mathrm{m}$. Cu-catalyzed $\mathrm{ZnO} \mathrm{NRs}$ exhibited a higher FE area factor of about $7.18 \times 10^{3}$ and a larger field adjustment factor of $1.21 \times 10^{-5}$ than the values of $\mathrm{Au}$-catalyzed NRs, which is due to the vertical direction growth of Cu-catalyzed NRs.

The role of metallic structures remained a subject of research. The work [116] shows investigations on FE from $\mathrm{ZnO} \mathrm{NRs}$ grown on polystyrene and polyethylene foils. It was shown that a few-nanometer thick $\mathrm{Au}$ film on top of the $\mathrm{ZnO} \mathrm{NR}$ lowers the electric field for electron emission significantly while gold films thicker than $25 \mathrm{~nm}$ have little effect on the FE properties. This is explained by additional field enhancement due to $\mathrm{Au}$ islands that are formed on top of the $\mathrm{ZnO} \mathrm{NRs}$.

In 2006, there were very interesting investigations about FE behavior of the ZnO NRs after thermal annealing in a different environments [117]. The Raman and PL results indicate that the crystal structure was improved by annealing in oxygen due to oxygen vacancy concentration reduction. Surface states correlative with oxygen vacancy in $\mathrm{ZnO}$ NRs can play a key role in determining the FE performance. The sample annealed in oxygen had better FE properties due to its better crystal structure, lower work function, and increased conductivity.

In 2004, two papers (by the same authors) appeared on the subject of FE from $\mathrm{ZnO}$ NRs grown on carbon cloth $[118,119]$. Extremely good results were obtained: an emission current density of $1 \mathrm{~mA} / \mathrm{cm}^{2}$ at an operating electric field of $0.7 \mathrm{~V} / \mu \mathrm{m}$. A comparative study of FE from NRs of various morphologies and site densities led to the conclusion that length, site density, and substrate geometry are vital factors in determining the FE properties.

In 2011, there were reports on studies of $\mathrm{ZnO}$ NRs grown on $\mathrm{G}$ as field emitters. This is extremely attractive for flexible applications, such as flexible displays and solar cells. In work [120] a hybrid material was demonstrated consisting of vertically aligned $\mathrm{ZnO}$ NRs grown hydrothermally on reduced G/PDMS substrates. The FE of this hybrid material showed low turn-on field values of $2.0 \mathrm{~V} / \mu \mathrm{m}, 2.4 \mathrm{~V} / \mu \mathrm{m}$, and $2.8 \mathrm{~V} / \mu \mathrm{m}$ (for convex, flat, and concave deformations, respectively). Such variations of FE properties were attributed to the modification of $\mathrm{ZnO}$ NRs emitter density upon mechanical deformation. The convex bending exhibited one of the lowest values of $2.0 \mathrm{~V} / \mu \mathrm{m}$, due to the reduced screening effect from neighboring field emitters.

Similar results were obtained in 2013. In work [102], $\mathrm{ZnO} \mathrm{NR}$ arrays were grown on a single side of flexible reduced graphene sheets (rGs) forming two-layered heterostructures of $\mathrm{ZnO} / \mathrm{G}$. Due to the outstanding mechanical and electrical properties of the rGs, two-layered $\mathrm{ZnO} / \mathrm{G}$ heterostructures were demonstrated to have excellent FE properties (turn-on field as low as $2.1 \mathrm{~V} / \mu \mathrm{m}$, the emitting current $470 \mu \mathrm{A} / \mathrm{cm}^{2}$ at $\left.3 \mathrm{~V} / \mu \mathrm{m}\right)$.

Although commercial field emitters are not built on a $\mathrm{ZnO}$ basis, it is believed this is a matter of time as $\mathrm{ZnO}$ NRs are one of the most promising nanostructures and soon we will see their practical applications extent to FE applications as well.

\section{Field effect transistor}

$\mathrm{ZnO} \mathrm{NRs}$, because of their unique electrical properties, are under investigation as an attractive candidate for a broad range of applications in new types of transparent electronics that operate with low power requirements, i.e. in FET.

The first true FET structure based on single ZnO NRs as a channel was fabricated using NRs grown by site selective MBE [121]. In the dark, this depletion-mode transistor exhibited good saturation behavior, a threshold voltage of $-3 \mathrm{~V}$, and a maximum transconductance of order $0.3 \mathrm{mS} / \mathrm{mm}$.

In the same year, a work was published on bottom-up integration of $\mathrm{ZnO} \mathrm{NRs}$ to obtain a vertical surroundgate FET [122]. The vertical device architecture has the potential for use in ultra-high-density nanoscale memory and logic devices. More significantly, scaling of the vertical channel length was lithographically independent and decoupled from the device packing density. A bottom electrical contact to the NR was uniquely provided by a heavily doped underlying lattice-match substrate.

Also in 2004, a very interesting result was presented - by simple polymer passivation of $n$-channel $\mathrm{ZnO}$ NR-based FET significantly improved its characteristics, and increased the current on/off ratio from 7 to $10^{4}$ $10^{5}$ and also increased transconductance from $140 \mathrm{nS}$ to $1.8 \mu \mathrm{S}$ [123]. The electron mobility estimated from 
transconductance exhibited a maximum value of 1000 $1200 \mathrm{~cm}^{2} /(\mathrm{V} \mathrm{s})$, which confirms the practicability of semiconductor oxide-based NRs for electronic nanodevice applications.

After 2 years, in 2016, a much better FET based on $\mathrm{ZnO} \mathrm{NR}$ was presented [124]. The applied $\mathrm{SiO}_{2} / \mathrm{Si}_{3} \mathrm{~N}_{4}$ passivation processes proved to significantly enhance device performance in the subthreshold swing, on/off ratio, and mobility. On average, the field effect mobility of $\mathrm{ZnO} \mathrm{NR}$ FETs is dramatically increased by two orders of magnitudes, with the maximum measured mobility exceeding $4000 \mathrm{~cm}^{2} /(\mathrm{V} \mathrm{s})$. The origin of the superior FET performance was attributed to passivation of surface defect states, which act as scattering and trapping centers, and reduction of surface adsorption processes at oxygen vacancy sites. Since mobility determines the carrier velocity and thus the switching speed, these NR FETs are of great potential for future applications in high-frequency integrated electronics, such as memory elements and logic gates.

Also in 2016, there was a very interesting work on the use of a $\mathrm{ZnO}$ NR-based transistor as a force detector in the nanoscale [125]. A new type of device, a piezoelectric FET composed of a $\mathrm{ZnO}$ NR bridging two ohmic contacts, was demonstrated, in which the source to drain current is controlled by the bending of the NR. A possible explanation of this phenomenon is suggested by association with the unique semiconducting and piezoelectric coupling effect of $\mathrm{ZnO}$. This device was demonstrated as a force sensor for measuring forces in the nanonewton range and even smaller with the use of smaller NRs. An almost linear relationship between the bending curvature and the conductance was found at small bending regions, demonstrating the principle of NR-based nanoforce sensors.

In 2008, a work was published on the high-current driving multiple ZnO NRs FETs [126]. The devices were simply formed by assembling ZnO NRs on a Si substrate using an optimized AC dielectrophoresis technique. These multiple $\mathrm{ZnO}$ NRs FETs exhibited very good electrical characteristics with a transconductance of $311.5 \mu \mathrm{S}$ at a drain voltage of $15 \mathrm{~V}$. This approach could find uses in a number of applications in the field of high-frequency integrated electronics.

$\mathrm{ZnO}$ is also very known for its sensor properties, i.e. the great influence of the chemical state of the surface (adsorption and desorption of multiple molecules) on electrical properties, which is particularly visible in the case of nanostructures, where the depleted layer can cover the entire volume of structures. Therefore, it is well suited for creating sensors based on a transistor with an open gate (based on the $\mathrm{ZnO}$ matrix) subjected to chemical coefficients.

The first demonstration of this idea was presented in 2004 [127]. $n$-type single crystal ZnO NRs were synthesized by a vapor trapping CVD and fabricated into NR FETs. $\mathrm{O}_{2}$ adsorption on the NR surface was shown to have a considerable effect on the measured conduc- tance, and an $\mathrm{O}_{2}$ sensing study showed that the sensitivity depends on NR diameter as well as applied gate voltage. In the following years, FET-based sensors were presented for different chemical compounds; e.g. in 2009 it was shown that the functionalized $\mathrm{ZnO}$ NRs on the surface of a silver wire connected as an extended gate area of an ordinary MOSFET can be used for the electrochemical detection of $\mathrm{Ca}^{2+}$ ions [128]. In 2013, the solutiongated FET-based sensors for the detection of cholesterol were demonstrated [129]. The FET sensors showed a good sensing performance in terms of wide-linear range and high sensitivity with a detection limit of $\approx 0.05 \mu \mathrm{M}$. In 2014, a FET hydrazine sensor was fabricated based on solution grown vertically-aligned $\mathrm{ZnO}$ NRs. In the case of $\mathrm{ZnO}$ NRs, however, the FET structure is not required for high-sensitive sensors, which allows sensor structure to be greatly simplified. These applications are presented in the next section.

\section{Chemical and biological sensors}

Oxide semiconductor gas sensors exhibit a conductance after adsorption of oxidizing gas or the electrochemical interaction between the reducing gas and adsorbed oxygen with a negative charge. The main strengths of oxide semiconductor gas sensors are high sensitivity, cost effectiveness, and reliability, all of which originate from their simple chemisorption sensing mechanism. However, the oxidative or reductive interactions of gases with the oxide semiconductor surface are often insufficient to recognize and quantify a specific gas. Thus, over the previous decades, many efforts have been directed at achieving gas selectivity as the addition of precious metals, oxide catalysts or control of sensor temperature or the use of a selective filtering layer. This chapter contains review of different approaches and sensor architectures.

\subsection{Detection of reducing gases}

$\mathrm{ZnO}$ is a typical $n$-type semiconductor and its conductivity is influenced by the surface depletion layer, especially for nanostructures such as NRs. Therefore, the mechanism of a $\mathrm{ZnO} \mathrm{NR}$ gas sensor is based on the change in resistance. The target gas molecules adsorb onto or desorb from the working material surface, causing resistivity changes, that is the sensor response and recovery process. When the sensor is placed in air, oxygen molecules will be adsorbed on the surface of $\mathrm{ZnO}$ and capture electrons from the surface layer and change into oxygen species $\left(\mathrm{O}_{2}^{-}, \mathrm{O}^{-}\right.$and $\left.\mathrm{O}^{2-}\right)$ creating depletion layer on the surface. The concentration of electrons, as the majority carrier, is very low and the resistance is relatively large. When some reducing compound, e.g. ethanol is injected into surface of NRs, oxygen species $\left(\mathrm{O}_{2}^{-}, \mathrm{O}^{-}\right.$and $\left.\mathrm{O}^{2-}\right)$ will react with the reducing gas [130]:

$$
\mathrm{C}_{2} \mathrm{H}_{5} \mathrm{OH}+6 \mathrm{O}^{-} \rightarrow 2 \mathrm{CO}_{2}+3 \mathrm{H}_{2} \mathrm{O}+6 \mathrm{e}^{-} .
$$

Oxygen species react with ethanol and release electrons back to the conduction band of $\mathrm{ZnO}$. The width of the 
electron depletion layer decreases, leading to decrease in the sensor resistance. This is the main sensing mechanism of $\mathrm{ZnO}$-based sensors.

The first demonstration of ZnO NRs as a highly sensitive gas sensor was published in 2004 [131]. The sensors were fabricated with the microelectromechanical system (MEMS) technology. High sensitivity and fast response time were found at a working temperature of $300^{\circ} \mathrm{C}$. The next paper on this subject was published in 2005 [132]. Presented in 2006 was a sensitivity of 18.9 to $200 \mathrm{ppm}$ of ethanol, response time and recovery times were 10 and $30 \mathrm{~s}$ respectively [133]. In the same year there was presented sensor based on $\mathrm{ZnO}$ NRs working at $350^{\circ} \mathrm{C}$ that can detect $1 \mathrm{ppm}$ of ethanol [134]. As the above example shows, the detection mechanism is mainly dependent on surface conditions that change with temperature. This way, the sensitivity is related with growth technology. Therefore, the selectivity of this type of sensors (of course, apart from the examples of specific functionalization) can be obtained by selecting the operating temperature. Also in 2006 a paper was presented demonstrating nanorods, which exhibit good sensing characteristics for $1000 \mathrm{ppm}$ of ethanol at or below $150^{\circ} \mathrm{C}$ [135]. Furthermore, the sensitivity remained essentially the same up to 1000 cycles. This application was under intense investigation over the next year. In 2007, sensors were presented based on the $\mathrm{ZnO}$ NRs with a sensing response to $1 \mathrm{ppm}$ ethanol of 3.2 [136]. The response times and the recovery times for ethanol gas were no more than $10 \mathrm{~s}$ when operating at $450^{\circ} \mathrm{C}$. In the same year, a very interesting study of the size dependence of gas sensitivity of $\mathrm{ZnO}$ NRs was presented [137]. While the high surface adsorption of oxygen is the key to obtaining excellent gas sensing performance by the sensor, it was found that the thinner $\mathrm{ZnO} \mathrm{NR}$ sensors have significantly better sensing performance due to the larger quantity of electron donors related with oxygen vacancies $\left(V_{\mathrm{O}}\right)$ and larger effective surface areas, resulting in a larger quantity of adsorbed oxygen than the thicker NRs sensors. Therefore, the thin well-aligned $\mathrm{ZnO}$ NRs would be of great potential for further practical applications in gas sensors. Only one year later, another paper described well aligned $\mathrm{ZnO}$ NRs with $20 \mathrm{~nm}$ diameter at the edge of terrace steps on the sapphire substrate [138]. This sensor exhibited the high surface-to-volume ratio of $58.6 \mu \mathrm{m}^{-1}$ and the significantly high sensitivity of about 10 even for the low ethanol concentration of $0.2 \mathrm{ppm}$ in room temperature. In the following years, several papers were presented on the use of pure ZnO NRs as an ethanol sensor [139-142].

In addition to modifying the size of the NRs, amplification of the sensor response can be obtained by adding metal NPs to the surface of the NRs. Metal NPs on NRs could increase the adsorption of oxygen molecules due to its spillover effect. This chemical mechanism of $\mathrm{Au}$ NPs will cause more electrons to be trapped and the electron depletion layer will be thicker. It will generate more oxygen species and more reactive points compared with the pure $\mathrm{ZnO}$. The first practical use of this solu- tion was published in 2007 [143]. The sensors fabricated from In-doped $\mathrm{ZnO}$ NRs exhibited high sensitivity and very fast response and recovery times $(\approx 2 \mathrm{~s})$. In the same year, a paper was presented on high-density single crystalline ZnO NRs with Pd NPs adsorbed on NR surfaces [144]. Compared with pure ZnO NRs, it was found that the sensor response of the $\mathrm{ZnO}$ NRs with $\mathrm{Pd}$ adsorption was much larger. Similar results were presented on Ag NPs embedded-ZnO NRs [145]. Gas-sensing property measurements had shown that, compared with the pure $\mathrm{ZnO}$, the synthesized $\mathrm{Ag}$ nanoparticle embedded$\mathrm{ZnO}$ NRs had an enhanced ethanol-sensing property. Finally, papers were published describing sensors based on $\mathrm{Au}$-functionalized ZnO NRs $[130,146]$. The Au/ZnO sensor manifests high response, fast response-recovery time and good repeatability, resulting from the combination of $1 \mathrm{D}$ nanostructure with unique properties of $\mathrm{Au}$ NPs. The superior sensing features indicate that the present $\mathrm{Au} / \mathrm{ZnO}$ NRs are promising as gas sensors.

Another approach is related to the change of $\mathrm{ZnO}$ band structure through doping. In 2008 there were presented sensors based on the $\mathrm{ZnO}$ and $\mathrm{Au}$-doped $\mathrm{ZnO}$ NRs [147]. It was found that the sensitivity of the sensor based on $\mathrm{Au}$-doped $\mathrm{ZnO}$ NRs exhibits higher values than that of the sensor based on undoped ZnO. Other authors used Co [148] or $\mathrm{Nd}$ ions as a dopant [149]. In the latter case, the gas-sensing properties of $\mathrm{ZnO}$ NRs were improved. The gas response of pure and 2 at.\% Nd-doped $\mathrm{ZnO}$ NRs to $100 \mathrm{ppm}$ ethanol vapor were 20.3 and 37.8 , respectively.

Very interesting results were obtained for $\mathrm{ZnO} \mathrm{NRs}$ in conjunction with graphene $(\mathrm{G})$. In 2011, a flexible gas sensor was presented using hybrid vertically grown $\mathrm{ZnO}$ NRs and free-standing G sheets [150]. This gas sensor enabled ppm level detection for ethanol vapor. The result suggests that the combination of $1 \mathrm{D}$ nanocrystals and two-dimensional $\mathrm{G}$ improves the performance of the sensors and imparts additional mechanical or optical functions to the devices. Studies on this subject were continued in the subsequent years, and in 2013 a paper was published with an analysis of single and double side $\mathrm{ZnO} / \mathrm{G}$ structure [102]. When the sensors are exposed to reducing gases, they can catalytically react with the adsorbed oxygen, freeing electrons to return to the $\mathrm{ZnO}$ surface and increasing the sensors' conductivity, thus, gases are detected. Gas molecules adsorbing on the active surface benefit from the $\mathrm{ZnO} / \mathrm{G}$ array structures, which will simplify molecular absorption, gas diffusion, and mass transport. Direct growth of the NRs onto the rGs substrates, highly aligned $\mathrm{ZnO}$ nanorods offer quantities of active centers and efficient electron pathways for amperometric sensors. Electrons flow from the rGs to the $\mathrm{ZnO}$ NRs, which causes the surface of the ZnO NRs to become more $n$-type than at the original state. The rGs substrates create a contact at the interface with $\mathrm{ZnO}$ which reduces the energy barrier between the gas and the rGs and make the electron transfer occur more easily. In addition, due to the high charge carrier mobility of rGs, 
it provides direct conduction paths for carriers to transport from the junction to the external electrode, and thus the electrical signals link closely and propagate rapidly.

Almost all the above examples presented a simple ethanol sensor, based on resistance measurement. Other, more sophisticated configurations are also possible. For example, in 2011 an ethanol sensor was presented using a $p$-type $\mathrm{Co}_{3} \mathrm{O}_{4}$-decorated $n$-type $\mathrm{ZnO} \mathrm{NR}$ network sensor via the formation of $p-n$ junctions [151]. The less agglomerated and porous network structures facilitate not only the rapid and effective diffusion of analyzed gases to the entire nanostructured surface but also the uniform loading of a sensitizer. Therefore, the coating of a discrete configuration of $p$-type semiconductors onto an $n$-type semiconductor NRs provides a simple, comprehensive, and powerful tool to control both the gas selectivity and the gas sensitivity. Two years later, a work was published describing synthesis of highly dense $p$-ZnO NPs $/ n$-ZnO NRs on a glass substrate [152]. The reaction produced more electrons at a higher temperature. These electrons increase the conductivity of $n$-type $\mathrm{NR}$ and reduce that of $p$-type NPs. The gas responses of $p$-ZnO NPs $/ n$-ZnO NRs are dominated by $p$-type sensing at $25^{\circ} \mathrm{C}$ and $n$-type sensing above $200^{\circ} \mathrm{C}$.

The commercially suitable approach was presented in 2010. It was an NRs based detector grown on silicon on insulator (SOI) complementary metal oxide semiconductor (CMOS) membranes [153]. The basic gas sensor device is a micro-hotplate structure containing a silicon micro-heater embedded in a thin dielectric membrane, which allows us to achieve high temperatures with low power consumption. The sensors were exposed to different concentrations of ethanol vapor in air (relative humidity $3000 \mathrm{ppm}$ ) and the sensitivities of $0.2 \% / \mathrm{ppm}$ and $0.1 \% / \mathrm{ppm}$ at $809 \mathrm{ppm}$ and $4563 \mathrm{ppm}$, respectively, were observed. The measurements were repeated at four different humidities and it was found that humidity has a significant effect on ethanol detection over the tested range.

All the above detectors were presented as ethanol sensors, but of course a similar mechanism works with other reducing gases, e.g. $\mathrm{H}_{2}$ gas. In 2005, a $\mathrm{ZnO}$ NRs-based detector sensitive to hydrogen at temperatures higher than $100^{\circ} \mathrm{C}$ was presented [154]. In recent years, there have been few papers on the detection of $\mathrm{H}_{2}$ by pure $\mathrm{ZnO}$ NRs [155-157].

Interesting results on $\mathrm{H}_{2}$ sensing were obtained by using single NR detectors. In 2008, paper was published on fabrication of $\mathrm{ZnO}$ NRs using nanoscale spacer lithography gas-sensing properties to $\mathrm{H}_{2}$ in the concentration range of 500-5000 ppm [158], but the technologies used rather preclude commercial application. Presented two years later was a single $\mathrm{ZnO} \mathrm{NRs}$ as a sensing material in nanosensors with a response to hydrogen gas at room temperature [159]. The same year, a study was presented on the influence on response and selectivity of the surface defect concentration and the diameter of $\mathrm{ZnO} \mathrm{NR}$ in single NR-detector at room temperature [160].
Another method to obtain selectivity to $\mathrm{H}_{2}$ at room temperature is coating $\mathrm{Pt}$ or $\mathrm{Pd}$ NPs on the surface of NRs to enhance the sensing mechanism. These NPs appear to be effective in catalytic dissociation of the $\mathrm{H}_{2}$ to atomic hydrogen. In the presence of hydrogen, chemisorbed oxygen ions are reduced to release electrons to the conduction band of the $\mathrm{ZnO}$ surface resulting in an increase in conductivity. In 2005, two papers were published by the same authors regarding $\mathrm{Pt}$ and $\mathrm{Pd}$ coated ZnO NRs detectors [161, 162]. These detectors were wellsuited to detection of ppm concentrations of hydrogen at room temperature. The recovery characteristics were fast upon removal of hydrogen from the ambient. But the slow response of the sensors at room temperature was a major issue to be solved. In 2006, another paper was published on the hydrogen sensing characteristics of different types of $\mathrm{ZnO}$ nanostructures, with and without impregnation of $\mathrm{Pt}$ [135]. The sensitivity to $\mathrm{H}_{2}$ sensors was upgraded in comparison to previous works. In 2010, a work was published on growth of $\mathrm{ZnO}$ NRs on fabric and their use as a hydrogen sensor [163]. The response and selectivity were enhanced and tuned with additives such as Pt-catalyst. The morphology and electrical characteristics of the NRs-on-fabric device were found to be robust against mechanical handling. The low cost and scalable fabrication process, room temperature sensing capabilities are very promising for future applications.

Similar mechanisms and solutions can be applied in case of detection of liquefied petroleum gas (LPG). The first information about the use of $\mathrm{ZnO} \mathrm{NRs}$ to detect LPG was published in 2005 [164], where in order to enhance the sensitivity and selectivity to LPG, NRs were coated with $\mathrm{PdO}$. The same solution was used in further studies [133]. In subsequent years also presented was the use of Pd coating to enhance the reaction to LPG [165]. The Pd-sensitized vertically aligned $\mathrm{ZnO}$ NRs were more selective to LPG in the presence of $\mathrm{CO}_{2}$ than vertically aligned $\mathrm{ZnO}$ NRs. In 2014, a paper was published presenting studies of the effects of aspect ratio of $\mathrm{ZnO} \mathrm{NRs}$ on the LPG sensing properties [166]. The LPG response increases along with the increasing aspect ratio of $\mathrm{ZnO}$ NRs. The high surface adsorption of oxygen is the important factor in the gas sensing phenomenon. It was found that sensors based on $\mathrm{ZnO}$ NRs with high aspect ratio provide high effective surface area and a larger number of electron donors related to $V_{\mathrm{O}}$, resulting in a larger number of oxygen adsorbed than $\mathrm{ZnO}$ NRs with low aspect ratios.

Recently, it was shown that $\mathrm{ZnO}$ NRs can also be applied to detect coal mine methane (CMM) [167]. It was shown that under UV irradiation, the operating temperature decreased from $225^{\circ} \mathrm{C}$ to $100^{\circ} \mathrm{C}$ for $\mathrm{ZnO}$ NRs. The sensor at room temperature $\left(25^{\circ} \mathrm{C}\right)$ under UV excitation showed an acceptable response $(\approx 23 \%)$ which makes its use in coal mines possible.

An example of another chemical compound which can be detected by $\mathrm{ZnO} \mathrm{NRs}$ is $\mathrm{H}_{2} \mathrm{~S}$. There are several 
reports in the literature about detection of this compound [134, 137, 164], also with use of Pd nanoparticles onto the surfaces of ZnO NRs [168], which leads to fabrication of $\mathrm{H}_{2} \mathrm{~S}$ sensors with a highly enhanced response and selectivity. In 2012, it was shown that selectivity to $\mathrm{H}_{2} \mathrm{~S}$ can be achieved by selecting the detector's operating temperature [169]. At $50{ }^{\circ} \mathrm{C}$, the response to $\mathrm{H}_{2} \mathrm{~S}$ was much higher than to LPG, CO, $\mathrm{CO}_{2}, \mathrm{O}_{2}$, ethanol, and $\mathrm{H}_{2}$.

Similar results were shown for carbon monoxide. There are many papers on the use of $\mathrm{ZnO}$ NRs to detect CO [155, 164, 170]. In paper [141] an example was presented how to increase selectivity by selecting operation temperature. Other methods reported for increasing sensitivity and selectivity to $\mathrm{CO}$ were Co-doping of NRs [148] or coating NPs with gold, which act as a catalyst in chemical sensitization and improve the sensing characteristics [171, 172].

Another example of a reducing chemical compound, which $\mathrm{ZnO} \mathrm{NRs}$ can be applied to detect is ammonia. There are many papers on simplearchitecture structures which present a response to $\mathrm{NH}_{3}[155,157,160,164,173,174]$, but particularly interesting are studies using $\mathrm{ZnO}$ NRs-coated quartz crystal microbalance $[175,176]$. The as-developed sensor showed a good response to $\mathrm{NH}_{3}$ gas at room temperature and it could be used to detect low level concentration of $\mathrm{NH}_{3}$ gas. Additionally, the sensor has a good selectivity to $\mathrm{NH}_{3}$ gas over various gases such as LPG, $\mathrm{N}_{2} \mathrm{O}, \mathrm{NO}_{2}$, $\mathrm{CO}$, and $\mathrm{CO}_{2}$

ZnO NRs are also sensitive to hydrazine. In 2008, the first paper was published on an electrochemical hydrazine sensor with a response time less than $5 \mathrm{~s}$ and a detection limit of $0.2 \mu \mathrm{M}$ [177]. One year later, a paper was presented about an ultra-sensitive hydrazine sensor fabricated by modifying a gold electrode with a high-aspectratio $\mathrm{ZnO} \mathrm{NR}$ grown by a simple thermal evaporation process at low temperature [178]. Response time was less than $5 \mathrm{~s}$ and a detection limit of $84.7 \mathrm{nM}$ was achieved. In 2014, a work on a FET hydrazine sensor based on vertically-aligned $\mathrm{ZnO}$ NRs was published [179]. The FET sensor exhibited good sensitivity with a low limit of detection $(\approx 3.86 \mathrm{nM})$, and a linear dynamic range (1 nM-60 $\mu \mathrm{M})$. These results, with their low-cost and ease of fabrication, show the great potential of $\mathrm{ZnO}$ NRs based detectors.

$\mathrm{ZnO} \mathrm{NRs}$ can also serve as humidity sensor. It is known that water vapor will be adsorbed on the surface of $\mathrm{ZnO} \mathrm{NRs}$ and reacts reversibly with $\mathrm{ZnO}$ as follows [180]:

$$
\mathrm{H}_{2} \mathrm{O}+2 \mathrm{Zn} \Leftrightarrow 2(\mathrm{OH}-\mathrm{Zn})+2 V_{\mathrm{O}}+2 \mathrm{e}^{-},
$$

where $\mathrm{V}_{\mathrm{O}}$ is the vacancy created at the oxygen site. With a strong local charge density and a strong electrostatic field, the ionic $\mathrm{Zn}_{2}$ will induce chemisorption followed by physisorption of water molecules. At high relative humidity, the naturally $n$-type $\mathrm{ZnO}$ NRs should become more conductive due to the increased number of free elec- trons. Due to high defect concentration, the first literature reports on humidity measurement by $\mathrm{ZnO} \mathrm{NRs}$ were achieved by doped $\mathrm{NRs}$, i.e. by $\mathrm{Cd}$ [181] or $\mathrm{Pt}$ doping [182]. Presented a few years later was a simple humidity sensor on pure ZnO NRs [183, 184] based on resistivity monitoring. It was also shown that detection of humidity based on quartz crystal microbalance coated with $\mathrm{ZnO}$ NRs is possible [185].

\subsection{Detection of oxidizing compounds}

The mechanism of the electrical response to oxidizing gases like $\mathrm{O}_{2}$ or $\mathrm{NO}_{2}$ is very simple. These gases adsorb directly on the surface of $\mathrm{ZnO}$ NRs. Therefore, the concentration of electrons on the surface of $\mathrm{ZnO}$ nanorods decreases and, correspondingly, the resistance of the $\mathrm{ZnO}$ layer increases. The process of the reaction can be described in the following example:

$$
\mathrm{NO}_{2}(\text { gas })+\mathrm{e}^{-} \rightarrow \mathrm{NO}_{2}(\text { ads })^{-} \text {. }
$$

The first publication presenting an $\mathrm{NO}_{2}$ detector based on $\mathrm{ZnO} \mathrm{NRs}$ was published in 2006 [186]. At the operating temperatures of 300 and $350^{\circ} \mathrm{C}$, the $\mathrm{ZnO} \mathrm{NRs}$ showed high $\mathrm{NO}_{2}$ sensitivity (1.8 for $1 \mathrm{ppm}$ of $\mathrm{NO}_{2}$ ) with negligible CO sensitivity (1.00-1.02), showing potential for use to detect $\mathrm{NO}_{2}$ in the presence of CO. In subsequent years, a few papers have appeared on the use of $\mathrm{ZnO} \mathrm{NRs}$ as an $\mathrm{NO}_{2}$ sensor based on resistivity changes [187-189], but a very interesting solution was published in 2009 [190] — ZnO-NRs gas sensors were presented, in which NR bridges were self-assembled between two electrodes by a selective growth of $\mathrm{ZnO} \mathrm{NRs}$ on patterned $\mathrm{Au}$ catalyst layers. The sensors demonstrated high gas response to $\mathrm{NO}_{2}$ down to the sub-ppm level and fast response/recovery behaviors. The gas response showed a maximum value at $225^{\circ} \mathrm{C}$ and linearly increased with the concentration of $\mathrm{NO}_{2}$ in the range of 0.5-3 ppm. The enhanced response of that sensor could be related with the formation of a potential barrier at the NR/NR junctions in addition to the effect of the increase in the surface depletion region of each NR and by the fact that $\mathrm{ZnO} \mathrm{NRs}$ are floated above the substrate and thus the adsorbed molecules can be easily desorbed from the surface of $\mathrm{ZnO}$.

An interesting approach was presented in 2007 [191], in which, next to the electrical response even at low operating temperatures, with detection limits lower than 200 ppm, optical properties were concerned. ZnO NRs PL spectra were reversibly quenched by the introduction of a few ppm of $\mathrm{NO}_{2}$ at $\mathrm{RT}$. $\mathrm{NO}_{2}$ adsorbed over the surface introduces non-radiative recombination paths that modify the emission properties of the NRs. These results were very promising for gas sensing applications even at room temperature.

In 2012, a study was published on the role of gold catalyst on the sensing behavior of $\mathrm{ZnO} \mathrm{NRs}$ for $\mathrm{NO}_{2}$ [192]. The presence of Au NPs on the surface of $\mathrm{ZnO}$ NRs does not enhance the response in case of $\mathrm{NO}_{2}$ gas. It was found that precious metals are not suitable for the oxidizing gases. 
An interesting approach was presented in 2011 [151] - selective detection of $\mathrm{NO}_{2}$ was achieved using a $p$ type $\mathrm{Co}_{3} \mathrm{O}_{4}$-decorated $n$-type $\mathrm{ZnO}$ NRs network sensor (this paper was also presented in part regarding ethanol sensors). The gas selectivity was explained by the catalytic effect of nanocrystalline $\mathrm{Co}_{3} \mathrm{O}_{4}$ and the extension of the electron depletion layer via the formation of $p-n$ junctions and the variation of sensor temperature. The coating of a $p$-type semiconductors onto $n$-type semiconductor NRs provides a simple tool to enhance selectivity and the gas sensitivity. One year later, a similar solution was published based on $\mathrm{ZnO}$ NRs modified with $\mathrm{SnO}_{2}$ NPs [193]. A $\mathrm{ZnO} / \mathrm{SnO}_{2}$ composite sensor exhibits a higher response to $\mathrm{NO}_{2}$ gas at room temperature under UV light irradiation. The $\mathrm{ZnO} / \mathrm{SnO}_{2}$ heterojunction model and the increased photo-generated electrons are beneficial for testing $\mathrm{NO}_{2}$ gas.

Of course, $\mathrm{ZnO}$ NRs can also be applied to detect oxygen, the adsorption of which on NRs surface is the first step to detecting reducing gases. The first report on $\mathrm{O}_{2}$ detection was achieved by FET with NRs as a channel [127]. $\mathrm{O}_{2}$ adsorption on the NR surface was shown to have a considerable effect on the measured conductance, and an $\mathrm{O}_{2}$ sensing study showed that the sensitivity depends on NR diameter as well as applied gate voltage. The following year, a report was presented on the use of individual $\mathrm{ZnO} \mathrm{NR}$ transistors fabricated and characterized in a vacuum chamber at different oxygen pressures [194]. The transistors exhibited high sensitivity to oxygen, which led to a change in the source drain current and a shift of the threshold voltage. It was shown that the sensing properties of the transistors are related to the trapping and releasing of the carriers in the NR.

$\mathrm{ZnO} \mathrm{NRs}$ appear well suited to detection of $\mathrm{O}_{3}$. It was shown [154] that they can be sensitive at temperatures as low as $25^{\circ} \mathrm{C}$ for percent levels of $\mathrm{O}_{3}$ in $\mathrm{O}_{2}$. The recovery characteristics are quite slow at room temperature, indicating that the NRs can be used only for initial detection of ozone. In 2010, a paper was presented on studies of various $\mathrm{ZnO}$ nanomaterials as sensitive to ozone, also low-defect $\mathrm{ZnO}$ single-crystal NRs [195]. At room temperature, responses reach about 1000 with the shortest response $T=60 \mathrm{~s}$ and recovery times $T=5 \mathrm{~s}$. The fast response and recovery time were attributed to the low defect density and high electron mobility of the singlecrystal nanorods. The sensor response was measured in the range from 1 to $2.5 \mathrm{ppm}$ ozone. The sensing mechanism of the $\mathrm{NO}_{2}$ gas is like ozone gas, but ozone possesses more oxidative ability than $\mathrm{NO}_{2}$, so the reaction in ozone is faster than $\mathrm{NO}_{2}$. Thus, the sensor response to ozone was higher.

\subsection{Biological sensors}

$\mathrm{ZnO}$ NRs have great potential not only in sensing simple gases, but also for more sophisticated detectors. In 2009, it was shown that the functionalized ZnO NRs on the surface of a silver wire connected as an extended gate area of an ordinary metal-oxide semiconductor FET
(MOSFET) can be used for the electrochemical detection of $\mathrm{Ca}^{2+}$ ions [128]. That same year, a paper was presented on formaldehyde detection at room temperature [196]. The results revealed that the response increases by more than two orders of magnitude to $110 \mathrm{ppm}$ formaldehyde with UV light irradiation. Such a high response was supposed to be caused by the photocatalytic reaction occurring between formaldehyde and adsorbed oxygen molecules. In 2010 , the possibility was presented of detecting hydrogen peroxide by modified electrode with a composite film of $\mathrm{ZnO}$ NRs and $\mathrm{Ag}$ NPs [197]. It was shown that the electro-reduction of $\mathrm{H}_{2} \mathrm{O}_{2}$ is a diffusion-controlled process catalyzed by $\mathrm{Ag}$ NPs. A linear relationship could be obtained between the current density and the concentration of $\mathrm{H}_{2} \mathrm{O}_{2}$ up to $1 \mathrm{mM}$, suggesting successful construction of a sensor for the detection of $\mathrm{H}_{2} \mathrm{O}_{2}$ for this concentration range. In turn, in 2012 hydroquinone detection by Ce-doped $\mathrm{ZnO}$ NRs was presented [198], and one year later solutiongated FET based sensors for the detection of cholesterol were demonstrated. The FET sensors showed a good sensing performance in terms of a wide-linear range and high sensitivity with a detection limit of $\approx 0.05 \mu \mathrm{M}$. In addition, the sensor shows low interference from electroactive species and was found to be dependable for cholesterol detection in human serum and whole blood samples [129].

The beginning of $\mathrm{ZnO}$ NRs in biological sensors started in 2006, when a paper on immobilization of uricase on $\mathrm{ZnO}$ NRs for a reagentless uric acid biosensor was published [199]. It was demonstrated that a threedimensional assembly with $\mathrm{ZnO}$ NRs achieved the direct electron transfer of uricase and showed excellent thermal stability. Two years later, detection of DNA sequences using nanoscale $\mathrm{ZnO}$ NRs arrays was presented [200]. The authors used covalent and non-covalent linking schemes in order to attach probe DNA strands to various $\mathrm{ZnO}$ nanoplatforms. After carrying out a duplex formation reaction with target DNA strands, fluorescence intensity was measured and compared. The presence of the underlying $\mathrm{ZnO}$ nanomaterials was critical in achieving increased fluorescence detection of hybridized DNA. This collective approach allowed detection of the target species B. anthracis at sample concentrations as low as a few femtomolar level and, therefore, permitted highly sensitive identification of the biothreat agent.

Also presented in 2006 was an enzymatic glucose biosensor based on $\mathrm{ZnO}$ NRs array functionalized by glucose oxidase $(\mathrm{GOx})$ with a low limit of detection of $0.01 \mathrm{mM}$, a response time of less than $5 \mathrm{~s}$, a linear range from 0.01 to $3.45 \mathrm{mM}$ [201]. These parameters demonstrate that $\mathrm{ZnO}$ NRs can provide a favorable microenvironment for GOx immobilization and stabilize its biological activity. This idea for a glucose sensor was under further development in subsequent years [202] and in 2010 a GOx functionalized sensor was presented with a fast response of less than $1 \mathrm{~s}$ and a quite wide linear range from 0.5 to $1000 \mu \mathrm{M}$ [203]. This sensor was charac- 
terized by stability, selectivity, and reproducibility. The same functionalization was used in the $\mathrm{ZnO}$ NR-gated region of an $\mathrm{AlGaN} / \mathrm{GaN}$ high-electron-mobility transistor structure with a very low limit of detection for glucose of $0.5 \mathrm{nM}$ [204]. This electronic detection of biomolecules is a significant step toward a compact sensor chip, which can be integrated with a commercially-available handheld wireless transmitter to realize a portable, fast response, and high sensitivity glucose detector.

A paper was presented in 2009 on a trimethylamine (TEA) gas sensor based on ZnO NRs [205]. Wellcrystallized $\mathrm{ZnO}$ NRs were employed by a facile solution route with benzene sulfonic acid sodium salt (DBS) as a modifying agent. The results demonstrated highly sensitive and selective to low-concentration (0.001-1000 ppm) TEA among the gases of ethanol, benzene, toluene, and acetone at the operating temperature of $150{ }^{\circ} \mathrm{C}$. The response of the $\mathrm{ZnO}$ sensor to $0.001 \mathrm{ppm}$ TEA was as high as 6 .

A very interesting approach was presented in 2015 [206]. Demonstrated was a novel electrochemiluminescence (ECL) immunosensor for sensitive and selective detection of carbohydrate antigen15-3(CA15-3) by using polyamidoamine (PAMAM)-functionalized $\mathrm{ZnO}$ NRs as carriers. The $\mathrm{ZnO} \mathrm{NRs}$ did not only catalyze $\mathrm{H}_{2} \mathrm{O}_{2}$ to produce various reactive oxygen species with an enhanced ECL signal but also had rich binding sites for loading large amounts of luminol. This immobilized luminol was further introduced onto the electrode surface through a sandwich-type immunoreaction resulting in higher luminol ECL efficiencies. Finally, Au NPs electrodeposited on the electrode not only provided a large surface area for the immobilization of abundant primary anti-CA15-3, but also facilitated electron transfer with increased ECL intensity. This procedure may provide a promising way for the simple and sensitive detection of other proteins as well.

\section{4. $p H$ detectors}

In 2005, it was shown that ZnO NRs can also be used for $\mathrm{pH}$ measurements [207]. ZnO NRs show dramatic changes in conductance upon exposure to polar liquids. The NRs exhibit a linear change in conductance between $\mathrm{pH} 2$ and 12 with a resolution of $0.1 \mathrm{pH}$ over the entire $\mathrm{pH}$ range. The results indicate that $\mathrm{ZnO}$ NRs may have applications in integrated chemical, gas, and fluid monitoring sensors. Two years later, a very interesting application was presented. $\mathrm{ZnO}$ NRs were used as electrochemical nanobiosensors to detect the intracellular $\mathrm{pH}$ of a human fat cell [208]. These results demonstrated the capability of performing biologically relevant measurements inside single living cells. The $\mathrm{ZnO} \mathrm{NR} \mathrm{pH}$ electrode thus holds promise for minimally invasive dynamic analyses of proton and hydroxyl groups in biochemical pathways within single living cells.

\subsection{Other sensor architectures}

Another approach to sensor architecture was presented in 2008. A gas sensor was demonstrated using $\mathrm{ZnO}$ NRs as the field ionization anode [209]. The sharp tips of the NRs generate very high electric fields at relatively low voltages and the breakdown voltage of $\mathrm{ZnO} \mathrm{NRs}$ is related with gas environment. This fact can be used in the construction of sensors for environmental monitoring and sensing in chemical processing plants.

In 2011, arrays of ZnO NRs decorated with Ag NPs were presented as 3D surface-enhanced raman scattering (SERS) substrates for detection of trace polychlorinated biphenyls (PCBs) [210]. The sharp top ends of the coneshaped $\mathrm{ZnO}$ NRs are essential for forming the special morphology of the particles and thus the high SERS activity. The supporting chemical enhancement effect of $\mathrm{ZnO}$ also makes a contribution to the SERS sensitivity. This 3D hybrid substrate manifests high SERS sensitivity to rhodamine and a detection limit as low as $10^{-11} \mathrm{M}$ to PCB 77. Three kinds of inter-Ag-NP gaps in 3D geometry create a huge number of SERS "hot spots" that mainly contribute to the high SERS sensitivity. Moreover, the supporting chemical enhancement effect of $\mathrm{ZnO}-\mathrm{NRs}$ and the better enrichment effect ascribed to the large surface area of the substrate also help to achieve a lower detection limit.

\section{Power nanogenerators}

This short section presents the last group of potential applications of $\mathrm{ZnO} \mathrm{NRs}$. The first application is mechanically powered transparent flexible chargegenerating nanodevices using the piezoelectric feature of $\mathrm{ZnO}$ [211]. Physical pressure on the top electrode generates a current density of $1 \mu \mathrm{A} \mathrm{cm}{ }^{-2}$, which is sufficient for use as a force/pressure sensor. It has clear potential for use in electrical applications such as touch screens and tactile skin sensors. In 2012, a simple approach was presented to convert low-frequency mechanical energy into electric power using piezoelectric $\mathrm{ZnO}$ NRs grown on a common paper substrate [212]. This energy conversion device could produce an output voltage of up to $10 \mathrm{mV}$ and an output current of about $10 \mathrm{nA}$. It was shown that the electrical output can be enhanced by scaling the size of the device. Very similar results were obtained for $\mathrm{ZnO}$ NRs grown on silver coated textile cotton fabrics [213]. The average output voltage generated from $\mathrm{ZnO}$ nanorods was measured to be around $9.5 \mathrm{mV}$. This energy-harvesting technology provides a simple and cost-effective platform to capture lowfrequency mechanical energy, such as body movements, for practical applications.

\section{Conclusions}

Despite of the vast number of scientific areas and extremely high-quality and interesting results, the real industrial use of $\mathrm{ZnO}$ NRs has not yet been observed. The serious step from laboratory investigations to industrial applications remains absent. The reason for this may be the inadequacy of the technologies used, as well as 
the complexity of the procedures and architectures in the presented solutions, which provide very good scientific results, but do not meet the conditions for commercial use, such as scalability or simply cost effectiveness. In recent years, however, new methods of growing $\mathrm{ZnO}$ nanostructures have been demonstrated (i.e. [19]), which are characterized by their unusual simplicity, ease of industrial implementation, low costs of both the equipment and the required materials (also their purity), and despite this, they guarantee extremely high crystallographic quality which is key for many applications. We believe that the development of such methods will be a huge impulse for the industrial implementation of $\mathrm{ZnO}$ NRs.

\section{References}

[1] C. Klingshirn, Phys. Status Solidi B 244, 3027 (2007).

[2] U. Ozgur, Ya.I. Alivov, C. Liu, A. Teke, M.A. Reshchikov, S. Dogan, V. Avrutin, S.J. Cho, H. Morkoc, J. Appl. Phys. 98, 041301 (2005).

[3] Z. Li, R. Yang, M. Yu, F. Bai, C. Li, Z.L. Wang, J. Phys. Chem. C 112, 20114 (2008).

[4] P. Yang, H. Yan, S. Mao, R. Russo, J. Johnson, R. Saykally, N. Morris, J. Pham, R. He, H. Choi, Adv. Funct. Mater. 12, 323 (2002).

[5] J.Y. Zhang, P.J. Li, H. Sun, X. Shen, T.S. Deng, K.T. Zhu, Q.F. Zhang, J.L. Wu, Appl. Phys. Lett. 93, 021116 (2008).

[6] B. Xiang, P.W. Wang, X.Z. Zhang, S.A. Dayeh, D.P.R. Aplin, C. Soci, D.P. Yu, D.L. Wang, Nano Lett. 7, 323 (2007).

[7] P.X. Gao, Y. Ding, Z.L. Wang, Nano Lett. 3, 1315 (2003).

[8] T. Sun, J. Qiu, C. Liang, J. Phys. Chem. C 112, 715 (2008).

[9] B.P. Zhang, N.T. Binh, K. Wakatsuki, Y. Segawa, Y. Yamada, N. Usami, M. Kawasaki, H. Koinuma, Appl. Phys. Lett. 84, 4098 (2004).

[10] Z.L. Wang, J. Phys. Condens. Matter 16, R829 (2004).

[11] M.S. Arnold, Ph. Avouris, Z.W. Pan, Z.L. Wang, J. Phys. Chem. B 107, 659 (2003).

[12] X.H. Kong, X.M. Sun, X.L. Li, Y.D. Li, Mater. Chem. Phys. 82, 997 (2003).

[13] X.Y. Kong, Z.L. Wang, Nano Lett. 3, 1625 (2003).

[14] W.L. Hughes, Z.L. Wang, Appl. Phys. Lett. 86, 043106 (2005).

[15] D.P. Norton, Y.W. Heo, M.P. Ivill, K. Ip, M.F. Pearton, S.J. Chisholm, T. Steiner, Mater. Today 7, 34 (2004).

[16] L. Vayssieres, Adv. Mater. 15, 464 (2003).

[17] Ł. Wachnicki, B.S. Witkowski, S. Gierałtowska, K. Kopalko, M. Godlewski, E. Guziewicz, Acta Phys. Pol. A 120, 905 (2011).

[18] J.B. Law, J.T. Thong, Appl. Phys. Lett. 88, 133114 (2006).

[19] B.S. Witkowski, L. Wachnicki, S. Gieraltowska, P. Dluzewski, A. Szczepanska, J. Kaszewski, M. Godlewski, Int. J. Nanotechnol. 11, 758 (2014).
[20] J. Black, H. Lockwood, S. Maybu, J. Appl. Phys. 34, 178 (1963).

[21] C. Klingshirn, Chem. Phys. Chem. 8, 82 (2007).

[22] J.-J. Wu, S.-C. Liu, Adv. Mater. 14, 215 (2002).

[23] B.D. Yao, Y.F. Chan, N. Wang, Appl. Phys. Lett. 81, 757 (2002).

[24] Y.S. Wang, P.J. Thomas, P. O'Brien, J. Phys. Chem. B 110, 21412 (2006).

[25] M.K. Yadav, M. Ghosh, R. Biswas, A.K. Raychaudhuri, A. Mookerjee, Phys. Rev. B 76, 195450 (2007).

[26] M.-C. Jeong, B.-Y. Oh, M.-H. Ham, J.-M. Myoung, Appl. Phys. Lett. 88, 202105 (2006).

[27] S.-H. Park, S.-H. Kim, S.-W. Han, Nanotechnology 18, 055608 (2007).

[28] R. Guo, J. Nishimura, M. Matsumoto, M. Higashihata, D. Nakamura, T. Okada, Appl. Phys. B 94, 33 (2009).

[29] X.-M. Zhang, M.-Y. Lu, Y. Zhang, L.-J. Chen, Z. L. Wang, Adv. Mater. 21, 2767 (2009).

[30] S.J. An, J.H. Chae, G.-C. Yi, G.H. Park, Appl. Phys. Lett. 92, 121108 (2008).

[31] K.-K. Kim, S. Lee, H. Kim, J.-C. Park, S.-N. Lee, Y. Park, S.-J. Park, S.-W. Kim, Appl. Phys. Lett. 94, 071118 (2009).

[32] H. Sun, Q.-F. Zhang, J.-L. Wu, Nanotechnology 17, 2271 (2006)

[33] R. Könenkamp, R.C. Word, C. Schlegel, Appl. Phys. Lett. 85, 6004 (2004).

[34] R. Konenkamp, R.C. Word, M. Godinez, Nano Lett 5, 2005 (2005).

[35] H. Guo, J. Zhou, Z. Lin, Electrochem. Commun. 10 , 146 (2008).

[36] J. Bao, M.A. Zimmler, F. Capasso, X. Wang, Z.F. Ren, Nano Lett. 6, 1719 (2006).

[37] M.H. Huang, S. Mao, H. Feick, H. Yan, Y. Wu, H. Kind, E. Weber, R. Russo, P. Yang, Science 292, 1897 (2001)

[38] S.F. Yu, C. Yuen, S.P. Lau, W.I. Park, G.-C. Yi, Appl. Phys. Lett. 84, 3241 (2004).

[39] M.A. Noginov, Solid-State Random Lasers, Springer, New York 2005.

[40] S. Chu, G. Wang, W. Zhou, Y. Lin, L. Chernyak, J. Zhao, J. Kong, L. Li, J. Ren, J. Liu, Nature Nanotechnol. 6, 506 (2011)

[41] H. Kind, H. Yan, B. Messer, M. Law, P. Yang, Adv. Mater. 14, 158 (2002).

[42] Y.W. Heo, B.S. Kang, L.C. Tien, D.P. Norton, F. Ren, J.R. La Roche, S.J. Pearton, Appl. Phys. A 80, 497 (2005).

[43] C. Soci, A. Zhang, B. Xiang, S.A. Dayeh, D.P.R. Aplin, J. Park, X.Y. Bao, Y.H. Lo, D. Wang, Nano Lett. 7, 1003 (2007).

[44] N. Kouklin, Adv. Mater. 20, 2190 (2008).

[45] G. Chai, O. Lupan, L. Chowb, H. Heinrich, Sens. Actuat. A 150, 184 (2009).

[46] S.E. Ahn, J.S. Lee, H. Kim, S. Kim, B.H. Kang, K.H. Kim, G.T. Kim, Appl. Phys. Lett. 84, 5022 (2004). 
[47] L. Luo, Y. Zhang, S.S. Mao, L. Lin, Sens. Actuat. A 127, 201 (2006).

[48] Y. Li, F.D. Valle, M. Simonnet, I. Yamada, J.-J. Delaunay, Nanotechnology 20, 045501 (2009).

[49] B.S. Witkowski, L. Wachnicki, S. Gieraltowska, P. Sybilski, K. Kopalko, M. Stachowicz, M. Godlewski, Phys. Status Solidi C 11, 1447 (2014).

[50] J.P. Kar, S.N. Das, J.H. Choi, Y.A. Lee, T.Y. Lee, J.M. Myoung, J. Cryst. Growth 311, 3305 (2009).

[51] F. Fang, J. Futter, A. Markwitz, J. Kennedy, Nanotechnology 20, 245502 (2009).

[52] Y. Li, F.D, Valle, M. Simonnet, I. Yamada, J.-J. Delaunay, Appl. Phys. Lett. 94, 023110 (2009).

[53] Y. Li, J. Gong, Y. Deng, Sens. Actuat. A 158, 176 (2010).

[54] S. Bai, W. Wu, Y. Qin, N. Cui, D.J. Bayer, X. Wang, Adv. Funct. Mater. 21, 4464 (2011).

[55] J.J. Hassan, M.A. Mahdi, S.J. Kasim, Naser M. Ahmed, H. Abu Hassan, Z. Hassan, Appl. Phys. Lett. 101, 261108 (2012).

[56] B.S. Witkowski, R. Pietruszka, S. Gieraltowska, L. Wachnicki, H. Przybylinska, M. Godlewski, OptoElectron. Rev. 25, 15 (2017).

[57] B. O'Regan, M. Grätzel, Nature 353, 737 (1991).

[58] M. Law, L.E. Greene, J.C. Johnson, R. Saykally, P. Yang, Nature Mater. 4, 455 (2005).

[59] J.B. Baxter, A.M. Walker, K. van Ommering, E.S. Aydil, Nanotechnology 17, S304 (2006).

[60] J. Tornow, K. Ellmer, J. Szarko, K. Schwarzburg, Thin Solid Films 516, 7139 (2008).

[61] Y.F. Hsu, Y.Y. Xi, A.B. Djurišić, W.K. Chan, Appl. Phys. Lett. 92, 133507 (2008).

[62] Z.H. Chen, Y.B. Tang, C.P. Liu, Y.H. Leung, G.D. Yuan, L.M. Chen, Y.Q. Wang, I. Bello, J.A. Zapien, W.J. Zhang, C.S. Lee, S.T. Lee, J. Phys. Chem. C 113, 13433 (2009).

[63] A. Umara, A. Al-Hajry, Y.B. Hahn, D.H. Kim, Electrochim. Acta 54, 5358 (2009).

[64] C.K.N. Peh, L. Ke, G.W. Ho, Mater. Lett. 64, 1372 (2010).

[65] S.H. Ko, D. Lee, H.W. Kang, K.H. Nam, J.Y. Yeo, S.J. Hong, C.P. Grigoropoulos, H.J. Sung, Nano Lett. 11, 666 (2011).

[66] D.-Y. Son, J.-H. Im, H.-S. Kim, N.-G. Park, J. Phys. Chem. C 118, 16567 (2014).

[67] A. Dymshits, L. Iagher, L. Etgar, Materials 9, 60 (2016).

[68] S. Li, P. Zhang, Y. Wang, H. Sarvari, D. Liu, J. Wu, Y. Yang, Z. Wang, Z.D. Chen, Nano Res. 10, 1092 (2017).

[69] C. Levy-Clement, R. Tena-Zaera, M.A. Ryan, A. Katty, G. Hodes, Adv. Mater. 17, 1512 (2005).

[70] K.S. Leschkies, R. Divakar, J. Basu, E. EnachePommer, J.E. Boercker, C. Barry Carter, U.R. Kortshagen, D.J. Norris, E.S. Aydil, Nano Lett. 7, 1793 (2007).

[71] Y. Tang, X. Hu, M. Chen, L. Luo, B. Li, L. Zhang, Electrochim. Acta 54, 2742 (2009).
[72] P. Ravirajan, A.M. Peiro, M.K. Nazeeruddin, M. Graetzel, D.D.C. Bradley, J.R. Durrant, J. Nelson, J. Phys. Chem. B 110, 7635 (2006).

[73] D.C. Olson, Y.-Ju Lee, M.S. White, N. Kopidakis, S.E. Shaheen, D.S. Ginley, J.A. Voigt, J.W.P. Hsu, J. Phys. Chem. C 111, 16640 (2007).

[74] K. Takanezawa, K. Hirota, Q.-S. Wei, K. Tajima, K. Hashimoto, J. Phys. Chem. C 111, 7218 (2007).

[75] H.E. Unalan, P. Hiralal, D. Kuo, B. Parekh, G. Amaratunga, M. Chhowalla, J. Mater. Chem. 18, 5909 (2008).

[76] Z. Yin, S. Wu, X. Zhou, X. Huang, Q. Zhang, F. Boey, H. Zhang, Small 6, 307 (2010).

[77] Y. Hames, Z. Alpaslan, A. Kosemen, S.E. San, Y. Yerli, Solar Energy 84, 426 (2010).

[78] A.J. Said, G. Poize, C. Martini, D. Ferry, W. Marine, S. Giorgio, F. Fages, J. Hocq, J. Boucle, J. Nelson, J.R. Durrant, J. Ackermann, J. Phys. Chem. C 114, 11273 (2010)

[79] P. Ruankham, T. Sagawa, H. Sakaguchi, S. Yoshikawa, J. Mater. Chem. 21, 9710 (2011).

[80] T.-J. Hsueh, S.-Y. Lin, W.-Y. Weng, C.-L. Hsu, T.-Y. Tsai, B.-T. Dai, J.-M. Shieh, Solar Energy Mater. Solar Cells 98, 494 (2012).

[81] S. Geißendorfer, M. Vehse, T. Voss, J.-P. Richters, B. Hanke, K. von Maydell, C. Agert, Solar Energy Mater. Solar Cells 111, 153 (2013).

[82] P. Aurang, O. Demircioglu, F. Es, R. Turan, H.E. Unalan, J. Am. Ceram. Soc. 96, 1253 (2013).

[83] H.-Y. Chen, H.-L. Lu, L. Sun, Q.-H. Ren, H. Zhang, X.-M. Ji, W.-J. Liu, S.-J. Ding, X.-F. Yang, D.W. Zhang, Sci. Rep. 6, 38486 (2016).

[84] R. Pietruszka, B.S. Witkowski, G. Luka, L. Wachnicki, S. Gieraltowska, K. Kopalko, E. Zielony, P. Bieganski, E. Placzek-Popko, M. Godlewski, Beilstein J. Nanotechnol. 5, 173 (2014).

[85] R. Pietruszka, B.S. Witkowski, S. Gieraltowska, P. Caban, L. Wachnicki, E. Zielony, K. Gwozdz, P. Bieganski, E. Placzek-Popko, M. Godlewski, Solar Energy Mater. Solar Cells 143, 99 (2015).

[86] R. Pietruszka, B.S. Witkowski, E. Zielony, K. Gwozdz, E. Placzek-Popko, M. Godlewski, Solar Energy 155, 1282 (2017).

[87] W. Jacak, E. Popko, A. Henrykowski, E. Zielony, K. Gwozdz, G. Luka, R. Pietruszka, B. Witkowski, L. Wachnicki, M. Godlewski, L.-B. Chang, M.J. Jeng, Solar Energy Mater. Solar Cells 147, 1 (2016).

[88] E. Placzek-Popko, K. Gwozdz, Z. Gumienny, E. Zielony, R. Pietruszka, B. S. Witkowski, Ł. Wachnicki, S. Gieraltowska, M. Godlewski, W. Jacak, L.B. Chang, J. Appl. Phys. 117, 193101 (2015).

[89] K. Gwozdz, E. Placzek-Popko, E. Zielony, K.M. Paradowska, R. Pietruszka, B.S. Witkowski, K. Kopalko, M. Godlewski, L.-B. Chang, J. Alloys Comp. 708, 247 (2017).

[90] P. Fernandez-Ibanez, J. Blanco, S. Malato, F. De Las Nieves, J. Water Res. 37, 3180 (2003).

[91] M.I. Cabrera, O.M. Alfano, A.E. Cassano, J. Phys. Chem. 100, 20043 (1996). 
[92] I. Poulios, D. Makri, X. Prohaska, Global NEST 1, 55 (1999).

[93] X. Zhang, J. Qin, Y. Xue, P. Yu, B. Zhang, L. Wang, R. Liu, Sci. Rep. 4, 4596 (2014).

[94] S. Baruah, M.A. Mahmood, M.T.Z. Myint, T. Bora, J. Dutta, Beilstein J. Nanotechnol. 1, 14 (2010).

[95] X. Qiu, G. Li, X. Sun, L. Li, X. Fu, Nanotechnology 19, 215703 (2008).

[96] T. Jia, W. Wang, F. Long, Z. Fu, H. Wang, Q. Zhang, J. Alloys Comp. 484, 410 (2009).

[97] J. Zhao, L. Wang, X. Yan, Y. Yang, Y. Lei, J. Zhou, Y. Huang, Y. Gu, Y. Zhang, Mater. Res. Bull. 46 1207 (2011)

[98] C. Wu, L. Shen, Y.-C. Zhang, Q. Huang, Mater. Lett. 65, 1794 (2011).

[99] R. Mohan, K. Krishnamoorthy, S.-J. Kim, Solid State Commun. 152, 375 (2012).

[100] R. Saravanan, V.K. Gupta, T. Prakash, V. Narayanan, A. Stephen, J. Mol. Liq. 178, 88 (2013).

[101] M. Faisal, A.A. Ismail, A.A. Ibrahim, H. Bouzid, S.A. Al-Sayari, Chem. Eng. J. 229, 225 (2013).

[102] R. Zou, G. He, K. Xu, Q. Liu, Z. Zhang, J. Hu, J. Mater. Chem. A 1, 8445 (2013).

[103] R.C. Pawar, C.S. Lee, Appl. Catal. B Environm. 144 57 (2014)

[104] S. Jung, K. Yong, Chem. Commun. 47, 2643 (2011).

[105] S.-M. Lam, J.-C. Sin, I. Satoshi, A.Z. Abdullah, A.R. Mohamed, Appl. Catal. A Gen. 471, 126 (2014).

[106] J.-J. Wu, C.-H. Tseng, Appl. Catal. B Environm. 66, 51 (2006).

[107] Y. Zhang, J. Xu, P. Xu, Y. Zhu, X. Chen, W. Yu, Nanotechnology 21, 285501 (2010).

[108] C. Ren, B. Yang, M. Wu, J. Xu, Z. Fu, Y. Lv, T. Guo, Y. Zhao, C. Zhu, J. Hazard. Mater. 182, 123 (2010).

[109] L. Dong, J. Jiao, D.W. Tuggle, J.M. Petty, S.A. Elliff, M. Coulter, Appl. Phys. Lett. 82, 1096 (2003).

[110] C.J. Lee, T.J. Lee, S.C. Lyu, Y. Zhang, H. Ruh, H.J. Lee, Appl. Phys. Lett. 81, 3648 (2002).

[111] S.H. Jo, J.Y. Lao, Z.F. Ren, R.A. Farrer, T. Baldacchini, J.T. Fourkas, Appl. Phys. Lett. 83, 4821 (2003).

[112] H. Ham, G. Shen, J.H. Cho, T.J. Lee, S.H. Seo, C.J. Lee, Chem. Phys. Lett. 404, 69 (2005).

[113] Y.W. Zhu, H.Z. Zhang, X.C. Sun, S.Q. Feng, J. Xu, Q. Zhao, B. Xiang, R.M. Wang, D.P. Yu, Appl. Phys. Lett. 83, 144 (2003).

[114] C. Ye, Y. Bando, X. Fang, G. Shen, D. Golberg, J. Phys. Chem. C 111, 12673 (2007).

[115] S.Y. Li, P. Lin, C.Y. Lee, T.Y. Tseng, J. Appl. Phys. 95, 3711 (2004).

[116] J.B. Cui, C.P. Daghlian, U.J. Gibson, R. Püsche, P. Geithner, L. Ley, J. Appl. Phys. 97, 044315 (2005).

[117] Q. Zhao, X.Y. Xu, X.F. Song, X.Z. Zhang, D.P. Yu, C.P. Li, L. Guo, Appl. Phys. Lett. 88, 033102 (2006).

[118] D. Banerjee, S.H. Jo, Z.F. Ren, Adv. Mater. 16, 2028 (2004).

[119] S.H. Jo, D. Banerjee, Z.F. Ren, Appl. Phys. Lett. 85, 1407 (2004)
[120] J.O. Hwang, D.H. Lee, J.Y. Kim, T.H. Han, B.H. Kim, M. Park, K. No, S.O. Kim, J. Mater. Chem. 21, 3432 (2011).

[121] Y.W. Heo, L.C. Tien, Y. Kwon, D.P. Norton, S.J. Pearton, B.S. Kang, F. Ren, Appl. Phys. Lett. 85, 2274 (2004).

[122] H.T. Ng, J. Han, T. Yamada, P. Nguyen, Y.P. Chen, M. Meyyappan, Nano Lett. 4, 1247 (2004).

[123] W.I. Park, J.S. Kim, G.-C. Yi, M.H. Bae, H.-J. Lee, Appl. Phys. Lett. 85, 5052 (2004).

[124] P.-C. Chang, Z. Fan, C.-J. Chien, D. Stichtenoth, C. Ronning, J.G. Lu, Appl. Phys. Lett. 89, 133113 (2006).

[125] X. Wang, J. Zhou, J. Song, J. Liu, N. Xu, Z.L. Wang, Nano Lett. 6, 2768 (2006)

[126] D.-I. Suh, S.-Y. Lee, J.-H. Hyung, T.-H. Kim, S.K. Lee, J. Phys. Chem. C 112, 1276 (2008).

[127] Z. Fan, D. Wang, P.-C. Chang, W.-Y. Tseng, J.G. Lu, Appl. Phys. Lett. 85, 5923 (2004).

[128] M.H. Asif, O. Nura, M. Willander, B. Danielsson, Biosens. Bioelectron. 24, 3379 (2009).

[129] R. Ahmad, N. Tripathy, Y.-B. Hahn, Biosens. Bioelectron. 45, 281 (2013).

[130] J. Guo, J. Zhang, M. Zhu, D. Ju, H. Xu, B. Cao, Sens. Actuat. B 199, 339 (2014).

[131] Q. Wan, Q.H. Li, Y.J. Chen, T.H. Wang, X.L. He J.P. Li, C.L. Lin, Appl. Phys. Lett. 84, 3654 (2004).

[132] T. Gao, T.H. Wang, Appl. Phys. A 80, 1451 (2005).

[133] X. Jiaqiang, C. Yuping, C. Daoyong, S. Jianian, Sens. Actuat. B 113, 526 (2006).

[134] C. Wang, X. Chu, M. Wu, Sens. Actuat. B 113, 320 (2006).

[135] C.S. Rout, S. Hari Krishna, S.R.C. Vivekchand, A. Govindaraj, C.N.R. Rao, Chem. Phys. Lett. 418 586 (2006).

[136] Y. Lv, L. Guo, H. Xu, X. Chu, Physica E 36, 102 (2007).

[137] Q. Zhao, T. Xie, L. Peng, Y. Lin, P. Wang, L. Peng, D. Wang, J. Phys. Chem. C 111, 17136 (2007).

[138] J.Y. Son, S.J. Lim, J.H. Cho, W.K. Seong, H. Kim, Appl. Phys. Lett. 93, 053109 (2008).

[139] J. Xu, Y. Zhang, Y. Chen, Q. Xiang, Q. Pan, L. Shi, Mater. Sci. Eng. B 150, 55 (2008).

[140] J. Chen, J. Li, J. Li, G. Xiao, X. Yang, J. Alloys Comp. 509, 740 (2011).

[141] P. Rai, H.-M. Song, Y.-S. Kim, M.-K. Song, P.-R. Oh, J.-M. Yoon, Y.-T. Yu, Mater. Lett. 68, 90 (2012).

[142] L. Wang, Y. Kang, X. Liu, S. Zhang, W. Huang, S. Wang, Sens. Actuat. B 162, 237 (2012).

[143] L.M. Li, C.C. Li, J. Zhang, Z.F. Du, B.S. Zou, H.C. Yu, Y.G. Wang, T.H. Wang, Nanotechnology 18 , 225504 (2007).

[144] T.-J. Hsueh, S.-J. Chang, C.-L. Hsu, Y.-R. Lin, I.C. Chen, Appl. Phys. Lett. 91, 053111 (2007).

[145] Q. Xiang, G. Meng, Y. Zhang, J. Xu, P. Xu, Q. Pana, W. Yu, Sens. Actuat. B 143, 635 (2010).

[146] C. Gu, L. Shanshan, J. Huang, C. Shi, J. Liu, Sens. Actuat. B 177, 453 (2013). 
[147] N. Hongsith, C. Viriyaworasakul, P. Mangkorntong, N. Mangkorntong, S. Choopun, Ceram. Int. 34, 823 (2008).

[148] Y.-J. Li, K.-M. Li, C.-Y. Wang, C.-I. Kuo, L.-J. Chen, Sens. Actuat. B 161, 734 (2012).

[149] Y. Cao, W. Pan, Y. Zong, D. Ji, Sens. Actuat. B 138, 480 (2009).

[150] J. Yi, J.M. Lee, W.I. Park, Sens. Actuat. B 155, 264 (2011).

[151] C.W. Na, H.-S. Woo, I-D. Kim, J.-H. Lee, Chem. Commun. 47, 5148 (2011).

[152] C.-L. Hsu, K.-C. Chen, T.-Y. Tsai, T-J. Hsueh, Sens. Actuat. B 182, 190 (2013).

[153] S. Santra, P.K. Guha, S.Z. Ali, P. Hiralal, H.E. Unalan, J.A. Covington, G.A.J. Amaratunga, W.I. Milne, J.W. Gardner, F. Udre, Sens. Actuat. B 146, 559 (2010).

[154] B.S. Kang, Y.W. Heo, L.C. Tien, D.P. Norton, F. Ren, B.P. Gila, S.J. Pearton, Appl. Phys. A 80, 1029 (2005).

[155] J.X. Wang, X.W. Sun, Y. Yang, H. Huang, Y.C. Lee, O.K. Tan, L. Vayssieres, Nanotechnology 17, 4995 (2006).

[156] L.-J. Bie, X.-N. Yan, J. Yin, Y.-Q. Duan, Z.-H. Yuan, Sens. Actuat. B 126, 604 (2007).

[157] C.C. Li, Z.F. Du, L.M. Li, H.C. Yu, Q. Wan, T.H. Wang, Appl. Phys. Lett. 91, 032101 (2007).

[158] H.-W. Ra, K.-S. Choi, J.-H. Kim, Y.-B. Hahn, Y.H. Im, Small 8, 1105 (2008).

[159] O. Lupan, G.A. Emelchenko, V.V. Ursaki, G. Chai, A.N. Redkin, A.N. Gruzintsev, I.M. Tiginyanu, L. Chow, L.K. Ono, B. Roldan Cuenya, H. Heinrich, E.E. Yakimov, Mater. Res. Bull. 45, 1026 (2010).

[160] O. Lupan, V.V. Ursaki, G. Chai, L. Chow, G.A. Emelchenko, I.M. Tiginyanu, A.N. Gruzintsev, A.N. Redkin, Sens. Actuat. B 144, 56 (2010).

[161] H.T. Wang, B.S. Kang, F. Ren, L.C. Tien, P.W. Sadik, D.P. Norton, S.J. Pearton, J. Lin, Appl. Phys. A 81, 1117 (2005).

[162] H.T. Wang, B.S. Kang, F. Ren, L.C. Tien, P.W. Sadik, D.P. Norton, S.J. Pearton, J. Lin, Appl. Phys. Lett. 86, 243503 (2005).

[163] Z.H. Lim, Z.X. Chia, M. Kevin, A.S.W. Wong, G.W. Ho, Sens. Actuat. B 151, 121 (2010).

[164] X. Jiaqiang, C. Yuping, L. Yadong, S. Jianian, J. Mater. Sci. 40, 2919 (2005).

[165] K.V. Gurav, P.R. Deshmukh, C.D. Lokhande, Sens. Actuat. B 151, 365 (2011).

[166] K.V. Gurav, M.G. Gang, S.W. Shin, U.M. Patil, P.R. Deshmukh, G.L. Agawane, M.P. Suryawanshi, S.M. Pawar, P.S. Patil, C.D. Lokhande, J.H. Kim, Sens. Actuat. B 190, 439 (2014).

[167] S. Kimiagar, V. Najafi, B. Witkowski, R. Pietruszka, M. Godlewski, Sci. Rep. 8, 16298 (2018).

[168] Y. Zhang, Q. Xiang, J. Xu, P. Xu, Q. Pan, F. Li, J. Mater. Chem. 19, 4701 (2009).

[169] S.D. Shinde, G.E. Patil, D.D. Kajale, V.B. Gaikwad, G.H. Jain, J. Alloys Comp. 528, 109 (2012).
[170] T.-J. Hsueh, Y.-W. Chen, S.-J. Chang, S.-F. Wang, C.-L. Hsu, Y.-R. Lin, T.-S. Lin, I.-C. Chen, Sens. Actuat. B 125, 498 (2007).

[171] S.-J. Chang, T.-J. Hsueh, I.-C. Chen, B.-R. Huang, Nanotechnology 19, 175502 (2008).

[172] R.K. Joshi, Q. Hu, F. Alvi, N. Joshi, A. Kumar, J. Phys. Chem. C 113, 16199 (2009).

[173] H. Zhang, J. Wu, C. Zhai, N. Du, X. Ma, D. Yang, Nanotechnology 18, 455604 (2007).

[174] B.K. Law, J.T.L. Thong, Nanotechnology 19, 205502 (2008).

[175] X. Wang, J. Zhang, Z. Zhu, Appl. Surf. Sci. 252, 2404 (2006)

[176] N. Van Quy, V.A. Minh, N. Van Luan, V.N. Hung, N. Van Hieu, Sens. Actuat. B 153, 188 (2011).

[177] A. Umar, M.M. Rahman, S.H. Kim, Y.-B. Hahn, Chem. Commun. 2, 166 (2008).

[178] A. Umar, M.M. Rahman, Y.-B. Hahn, Talanta 77 1376 (2009).

[179] R. Ahmad, N. Tripathy, D.-U.-J. Jung, Y.-B. Hahn, Chem. Commun. 50, 1890 (2014).

[180] W.P. Tai, J.H. Oh, J. Mater. Sci. Mater. Electron. 13, 391 (2002).

[181] Q. Wan, Q.H. Li, Y.J. Chen, T.H. Wang, X.L. He, X.G. Gao, J.P. Li, Appl. Phys. Lett. 84, 3085 (2004).

[182] Y. Zhang, K. Yu, D. Jiang, Z. Zhu, H. Genge, L. Luo, Appl. Surf. Sci. 242, 212 (2005).

[183] Q. Qi, T. Zhang, Q. Yu, R. Wang, Y. Zeng, L. Liu, H. Yang, Sens. Actuat. B 133, 638 (2008).

[184] S.-P. Chang, S.-J. Chang, C.-Y. Lu, M.-J. Li, C.L. Hsu, Y.-Z. Chiou, T.-J. Hsueh, I.-C. Chen, Superlatt. Microstruct. 47, 772 (2010).

[185] Y. Zhang, K. Yu, S. Ouyang, L. Luo, H. Hu, Q. Zhang, Z. Zhu, Physica B 368, 94 (2005).

[186] P.-S. Cho, K.-W. Kim, J.-H. Lee, J. Electroceram. 17, 975 (2006).

[187] C.-J. Chang, S.-T. Hung, C.-K. Lin, C.-Y. Chen, E.H. Kuo, Thin Solid Films 519, 1693 (2010).

[188] B. Shouli, L. Xin, L. Dianqing, C. Song, L. Ruixian, C. Aifan, Sens. Actuat. B 153, 110 (2011).

[189] S. Park, S. An, H. Ko, C. Jin, C. Lee, Appl. Mater. Interfaces 4, 3650 (2012).

[190] M.-W. Ahn, K.-S. Park, J.-H. Heo, D.-W. Kim, K.J. Choi, J.-G. Park, Sens. Actuat. B 138, 168 (2009).

[191] E. Comini, C. Baratto, G. Faglia, M. Ferroni, G. Sberveglieri, J. Phys. D Appl. Phys. 40, 7255 (2007).

[192] P. Rai, Y.-S. Kim, H.-M. Song, M.-K. Song, Y.-T. Yu, Sens. Actuat. B 165, 133 (2012).

[193] G. Lu, J. Xu, J. Sun, Y. Yu, Y. Zhang, F. Liu, Sens. Actuat. B 162, 82 (2012).

[194] Q.H. Li, Y.X. Liang, Q. Wan, T.H. Wang, Appl. Phys. Lett. 85, 6389 (2004).

[195] F. S.-S. Chien, C.-R. Wang, Y.-L. Chan, H.-L. Lin, M.-H. Chen, R.-J. Wu, Sens. Actuat. B 144, 120 (2010).

[196] L. Peng, Q. Zhao, D. Wang, J. Zhai, P. Wang, S. Pang, T. Xie, Sens. Actuat. B 136, 80 (2009). 
[197] C.-Y. Lin, Y.-H. Lai, A. Balamurugan, R. Vittal, C.W. Lin, K.-C. Ho, Talanta 82, 340 (2010).

[198] G.N. Dar, A. Umar, S.A. Zaidi, A.A. Ibrahim, M. Abaker, S. Baskoutas, M.S. Al-Assiri, Sens. Actuat. B 173, 72 (2012).

[199] F. Zhang, X. Wang, S. Ai, Z. Sun, Q. Wan, Z. Zhu, Y. Xian, L. Jin, K. Yamamoto, Analyt. Chim. Acta 519, 155 (2004).

[200] N. Kumar, A. Dorfman, J. Hahm, Nanotechnology 17, 2875 (2006).

[201] A. Wei, X.W. Sun, J.X. Wang, Y. Lei, X.P. Cai, C.M. Li, Z.L. Dong, W. Huang, Appl. Phys. Lett. 89 123902 (2006).

[202] J. Liu, C. Guo, C.M. Li, Y. Li, Q. Chi, X. Huang, L. Liao, T. Yu, Electrochem. Commun. 11, 202 (2009).

[203] S.M.U. Ali, O. Nur, M. Willander, B. Danielsson, Sens. Actuat. B 145, 869 (2010).

[204] B.S. Kang, H.T. Wang, F. Ren, S.J. Pearton, T.E. Morey, D.M. Dennis, J.W. Johnson, P. Rajagopal, J.C. Roberts, E.L. Piner, K.J. Linthicum, Appl. Phys. Lett. 91, 252103 (2007).

[205] Y. Lv, C. Li, L. Guo, F. Wang, Y. Xu, X. Chu, Sens. Actuat. B 141, 85 (2009).
[206] X. Jiang, H. Wang, R. Yuan, Y. Chai, Biosens. Bioelectron. 63, 33 (2015).

[207] B.S. Kang, F. Ren, Y.W. Heo, L.C. Tien, D.P. Norton, S.J. Pearton, Appl. Phys. Lett. 86, 112105 (2005).

[208] S.M. Al-Hilli, M. Willander, A. Ost, P. Stralfors, J. Appl. Phys. 102, 084304 (2007).

[209] L. Liao, H.B. Lu, M. Shuai, J.C. Li, Y.L. Liu, C. Liu, Z.X. Shen, T. Yu, Nanotechnology 19, 175501 (2008).

[210] H. Tang, G. Meng, Q. Huang, Z. Zhang, Z. Huang, C. Zhu, Adv. Funct. Mater. 22, 218 (2012).

[211] M.-Y. Choi, D. Choi, M.-J. Jin, I. Kim, S,-H. Kim, J.-Y. Choi, S. Y. Lee, J. M. Kim, S.-W. Kim, Adv. Mater. 21, 2185 (2009).

[212] Y. Qiu, H. Zhang, L. Hu, D. Yang, L. Wang, B. Wang, J. Ji, G. Liu, X. Liu, J. Lin, F. Li, S. Han, Nanoscale 4, 6568 (2012).

[213] A. Khan, M.A. Abbasi, M. Hussain, Z.H. Ibupoto, J. Wissting, O. Nur, M. Willander, Appl. Phys. Lett. 101, 193506 (2012). 